\title{
Field-Scale Water Flow Simulations Using Ensembles of Pedotransfer Functions for Soil Water Retention
}

\author{
A. K. Guber, Ya. A. Pachepsky,* M. Th. van Genuchten, W. J. Rawls, J. Simunek, D. Jacques, \\ T. J. Nicholson, and R. E. Cady
}

\begin{abstract}
Using pedotransfer functions (PTF) to estimate soil hydraulic properties may be necessary in soil water flow simulations for large-scale projects or in pilot studies. The accuracy of a PTF outside of its development dataset is generally unknown. The existence of multiple models that are developed and tested in one region, but may perform relatively poorly in other regions, is also common in meteorology, where multimodel ensemble prediction techniques have been developed (i.e., those using an averaged prediction from several models) to address this problem. The objective of this work was to estimate the applicability of an ensemble of PTFs for water regime simulations. Measured soil water contents and pressure heads of 60 points at five depths in a 6-m transect of a layered loamy soil were collected during an extremely wet year in Belgium. Soil water fluxes were measured with passive capillary lysimeters at two depths. Water retention was measured in the laboratory on samples taken at 60 locations at three depths. Contents of soil textural fractions, organic matter content, and bulk density were averaged across the transect and used as input in the ensemble of 22 published PTFs developed from large datasets in different regions. The HYDRUS-1D software was used to simulate water content time series with (i) each of the PTFs from the ensemble and (ii) the laboratory-measured water retention data of each of the 60 locations. Simulations with the PTF ensemble had, on average, two times smaller errors those from using laboratory data. A possible explanation for this is that the PTF estimation gave substantially better approximations of field water retention than the laboratory data. The ensemble prediction appears to be a promising source of soil hydraulic properties to simulate soil water dynamics.
\end{abstract}

$\mathrm{S}$ IMULATIONS of soil water flow are often performed with parameters estimated using PTFs, which are empirical relationships between the soil hydraulic properties and more easily obtainable basic soil properties available, for example, from soil surveys. The use of PTFs is necessary when the simulations have to be done for large-scale projects or for pilot studies.

Applying PTFs always introduces substantial uncertainty because the accuracy of a PTF outside of its development dataset is unknown. Schaap and Leij (1998) demonstrated the dependence of pedotransfer predictions on the development database. They worked with

A.K. Guber and J. Simunek, Dep. of Earth and Environmental Sciences, Univ. of California, Riverside, CA 92521. Ya.A. Pachepsky, USDA-ARS, Environmental Microbial Safety Lab., BARC-East, 173 Powder Mill Rd., Beltsville, MD 20705. M.Th. van Genuchten, USDAARS, George E. Brown, Jr. Salinity Lab., Riverside, CA. W.J. Rawls, USDA-ARS Hydrology and Remote Sensing Lab., Beltsville, MD. D. Jacques, SCK-CEN, Belgium. T.J. Nicholson and R.E. Cady, USNRC, ONRR, Washington, DC. Received 14 Sept. 2005. *Corresponding author (ypachepsky@anri.barc.usda.gov).

Published in Vadose Zone Journal 5:234-247 (2006).

Special Section: From Field- to Landscape-Scale Vadose Zone Processes doi:10.2136/vzj2005.0111

(c) Soil Science Society of America

677 S. Segoe Rd., Madison, WI 53711 USA three large soil hydraulic property databases, and used a powerful tool-neural networks - to develop a water retention PTF for each of the databases. They subsequently tested the functions against data from the other two databases, and found that while the RMSE of water content estimates was only $0.06 \mathrm{~m}^{3} \mathrm{~m}^{-3}$ for the development database, it was as large as $0.12 \mathrm{~m}^{3} \mathrm{~m}^{-3}$ for the testing databases. Similar results were obtained in other comparisons of pedotransfer predictions and measured soil hydraulic properties (Tietje and Tapkenhinrichs, 1993; Wösten et al., 2001). There are indications that similarities in geographical settings may cause similarities in PTFs (Pachepsky et al., 1999), but such observations are scarce and it is not clear how general they are.

The existence and use of multiple models that are developed and tested in one region but perform relatively poorly in other regions is fairly common in meteorology (Molteni et al., 1996). Justifying the selection of a single model has become an unsolvable problem. The multimodel ensemble prediction method was developed during the last decade to address this dilemma (Houtemaker et al., 1996; Palmer et al., 2004). The basic idea of the method is straightforward since it involves the use of several models and simply averaging prediction from those models. The argument is that at present no underlying theoretical formalism exists from which a probability distribution of model uncertainty can be estimated, and hence that a pragmatic approach is need. One such approach relies on the fact that different research groups have developed climate models somewhat independently. An ensemble comprising such quasiindependent models is referred to as a multimodel ensemble (Palmer et al., 2004). Ensemble forecasts offer a way of filtering the predictable from the unpredictable through averagingfeatures that are consistent among ensemble members are then preserved, while those that are inconsistent are reduced in amplitude. Perhaps more important, the ensemble itself, as a sample from possible forecast outcomes, can be used to estimate the forecast uncertainty and the likely structure of forecast errors (Hamill et al., 2004).

Multimodel ensemble methods are now slowly also being used in subsurface hydrology. Ye et al. (2004) suggested averaging of spatial variability models in unsaturated fractured tuff for situations when standard information criteria provide an ambiguous ranking of the models, such that it is not justified to select one of them while discarding all others. Several general approaches to multimodel predictions now also exist (e.g., Burnham and Anderson, 1998).

The objective of this work was to estimate applicability of an ensemble of PTFs for simulation of field water

\footnotetext{
Abbreviations: PTF, pedotransfer function.
} 
regime. We will compare PTF-estimated results with measured soil water retention data from a well-instrumented field site in Belgium.

\section{MATERIALS AND METHODS \\ Soil Water Flow Experiment}

The experimental field was located in a meadow near Bekkevoort, Belgium, at the bottom of a $4 \%$ slope. The soil was classified as Eutric Regosol (FAO, 1998). Typically the top $1 \mathrm{~m}$ includes three soil horizons: an Ap horizon between 0 and $25 \mathrm{~cm}$, a $\mathrm{C} 1$ horizon between 25 and $55 \mathrm{~cm}$, and a $\mathrm{C} 2$ horizon between 55 and $100 \mathrm{~cm}$. A trench, $1.2 \mathrm{~m}$ deep and $8 \mathrm{~m}$ long, was excavated at the field site. Soil texture was measured with the pipette method following pretreatment with $\mathrm{Na}$ hexametaphosphate. Textural classes were loam at the 15-, 35-, and $55-\mathrm{cm}$ sampling depths, and silty loam at the $75-$ and $95-\mathrm{cm}$ depths (Table 1). The grass cover was removed from the experimental area. A plastic sheet covered the side of the trench where equipment was installed. Volumetric water contents were measured with TDR. Sixty TDR probes (two rods, $25 \mathrm{~cm}$ long, $0.5-\mathrm{cm}$ rod diameter, $2.5-\mathrm{cm}$ rod spacing) were installed along the trench at 12 locations with $50-\mathrm{cm}$ spacing at five depths $(15,35,55,75$, and $95 \mathrm{~cm}$ deep). The TDR measurements were done with a Tektronix 1502B cable tester (Beaverton, OR). The automated system of Heimovaara and Bouten (1990) was used to control, retrieve, store, and analyze measurements of the travel time of an electromagnetic wave along the TDR rods. One measurement cycle for all two-rod TDR probes took approximately $35 \mathrm{~min}$, while the time difference between two measurements for the same probe was $2 \mathrm{~h}$. Triplets of passive capillary samplers (PCAPS) were installed at the 15- and $55-\mathrm{cm}$ depths at a distance of about $5 \mathrm{~m}$ from the trench to measure soil water fluxes once every two to $3 \mathrm{~d}$. Pressure heads were measured with tensiometers. Tensiometric porous cups (6-mm diameter, $25 \mathrm{~mm}$ long) were installed at a horizontal distance of $10 \mathrm{~cm}$ from each of the 60 TDR probes. The porous caps were connected with waterfilled tubes to pressure transducers. Measurements of the pressure transducers were controlled and stored using a Campbell (Logan, UT) CR10X datalogger and AM416 multiplexers. Rainfall was measured and recorded continuously near the trench over the catch area of $200 \mathrm{~cm}^{2}$ (Fig. 1).

The trench was filled after all devices were installed. A thin layer of gravel $(1-2 \mathrm{~cm})$ was evenly distributed on the study area to (i) decrease the erosive effect of rain impact on the bare soil surface, (ii) minimize evaporation from the soil surface, and (iii) decrease the growth of weeds on the experimental plot. Weeds were regularly removed from the site during the summer. Field measurements started on 11 Mar. 1998 (Day 0) and concluded on 31 Mar. 1999 (Day 384). Additional details about the site and the experiment are given by Jacques (2000) and Jacques et al. (2001).

Table 1. Average values of soil properties at the monitoring depths.

\begin{tabular}{|c|c|c|c|c|c|c|c|c|}
\hline \multirow[b]{2}{*}{ Depth } & \multirow[b]{2}{*}{$\begin{array}{c}\text { No. of } \\
\text { samples }\end{array}$} & \multicolumn{5}{|c|}{ Diameters of soil textural fractions } & \multirow[b]{2}{*}{$\begin{array}{c}\text { Bulk } \\
\text { density }\end{array}$} & \multirow[b]{2}{*}{$\underset{\mathbf{C}}{\text { Organic }}$} \\
\hline & & $\begin{array}{l}>\mathbf{5 0} \\
\mu \mathrm{m}\end{array}$ & $\begin{array}{c}\text { 50-20 } \\
\mu \mathrm{m}\end{array}$ & $\begin{array}{c}20-10 \\
\mu \mathrm{m}\end{array}$ & $\begin{array}{c}10-2 \\
\mu \mathrm{m}\end{array}$ & $\begin{array}{l}<2 \\
\boldsymbol{\mu} \mathbf{m}\end{array}$ & & \\
\hline cm & & & & & & & $\mathrm{g} \mathrm{cm}^{-3}$ & $\%$ \\
\hline 15 & 7 & 58.6 & 19.3 & 6.4 & 4.5 & 11.1 & 1.42 & 2.2 \\
\hline 35 & 8 & 56.7 & 18.9 & 7.8 & 3.2 & 13.3 & 1.54 & 0.8 \\
\hline 55 & 5 & 57.3 & 17.6 & 6.6 & 3.7 & 14.8 & 1.53 & 0.4 \\
\hline 75 & 3 & 49.6 & 21.2 & 7.9 & 4.4 & 17.4 & 1.53 & 0.3 \\
\hline 95 & 4 & 43.8 & $\mathbf{3 0 . 0 3}$ & 7.4 & 4.5 & 14 & $\mathbf{1 . 5 3}$ & 0.6 \\
\hline
\end{tabular}

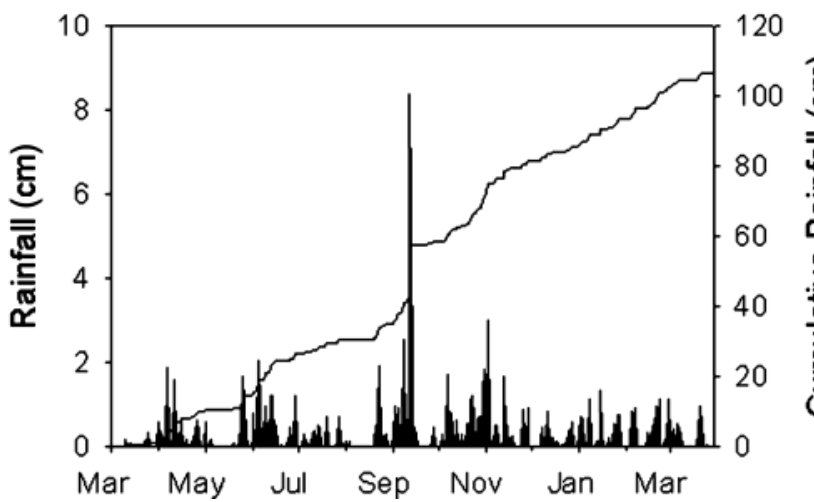

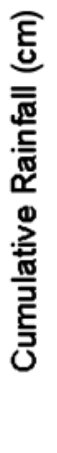

Fig. 1. Precipitation during the period of measurements.

A separate study of the soil hydraulic properties was performed along a $30-\mathrm{m}$ trench in the same soil at an adjacent site (Mallants et al., 1996). Undisturbed 5-cm-long and 5.1-cmdiameter cores were taken from three horizons: from the Ap horizon at $10 \mathrm{~cm}$ depth, $\mathrm{C} 1$ at $50 \mathrm{~cm}$ and $\mathrm{C} 2$ at $90 \mathrm{~cm}$ with alternating lateral sampling distances of 0.1 and $0.9 \mathrm{~m}$. Values of van Genuchten parameters were estimated from the water retention data obtained with a sand-box apparatus for capillary pressures of $1,5,10,50$, and $100 \mathrm{~cm}$, and with a pressure cell for pressures of $200,630,2500$, and $15000 \mathrm{~cm}$. The van Genuchten water retention equation (van Genuchten, 1980)

$$
\frac{\theta-\theta_{\mathrm{r}}}{\theta_{\mathrm{s}}-\theta_{\mathrm{r}}}=\frac{1}{\left[1+(\alpha h)^{n}\right]^{m}}
$$

was fitted to the data from each sample. In Eq. [1], $\theta$ is the volumetric water content, $h$ is the capillary pressure (the absolute value of the matric potential), $\theta_{\mathrm{s}}$ is the saturated water content, $\theta_{\mathrm{r}}$ is the residual water content, and $\alpha, m$, and $n$ are empirical shape-defining parameters. Statistics of the van Genuchten parameters along the trench are shown in Table 2. Values of the saturated hydraulic conductivity $K_{\mathrm{s}}$ were measured for each sample using a constant head permeameter (Klute, 1965).

\section{Ensemble of Pedotransfer Functions}

The literature was searched for PTFs to estimate soil water retention and soil hydraulic conductivity from soil data avail-

Table 2. Statistics of van Genuchten water retention parameters and the saturated hydraulic conductivity along the 30-m trench (Mallants et al., 1996).

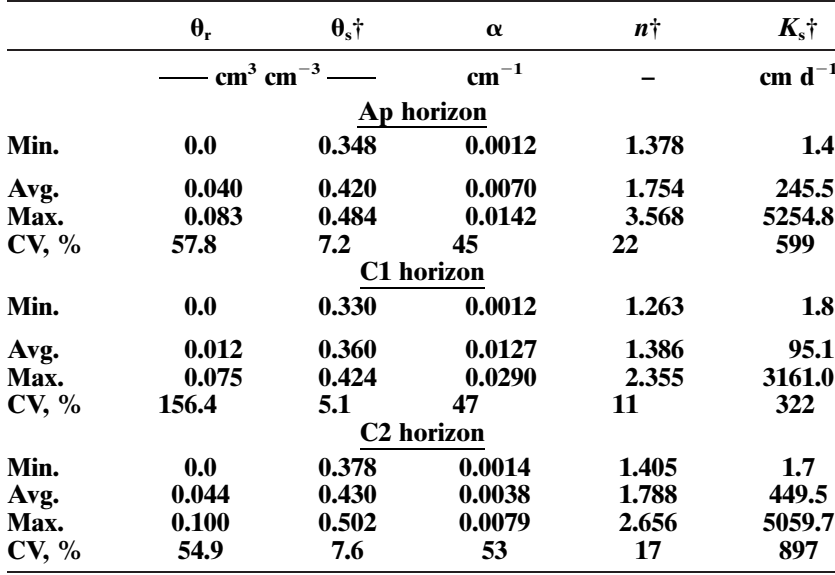

$\dagger \mathrm{CV}$ was calculated using $\log _{\mathrm{e}}$-transformed data. 
Table 3. Median and spread of the saturated hydraulic conductivity $K_{\mathrm{s}}\left(\mathrm{cm} \mathrm{d}^{-1}\right)$ for 12 USDA textural classes (after Rawls et al., 1998).

\begin{tabular}{|c|c|c|c|c|c|c|}
\hline \multirow[b]{2}{*}{$\begin{array}{l}\text { USDA } \\
\text { textural class }\end{array}$} & \multicolumn{3}{|c|}{$\begin{array}{c}\text { Soils with } \\
\text { high porosity }\end{array}$} & \multicolumn{3}{|c|}{$\begin{array}{c}\text { Soils with } \\
\text { low porosity }\end{array}$} \\
\hline & $K_{\mathrm{s} 50 \%}$ & $\boldsymbol{K}_{\mathrm{s} 75 \%}-\boldsymbol{K}_{\mathrm{s} 25 \%}$ & $\begin{array}{c}\text { Avg. } \\
\text { porosity }\end{array}$ & $K_{\mathrm{s50}} \%$ & $\boldsymbol{K}_{\mathrm{s} 75 \%}-\boldsymbol{K}_{\mathrm{s} 25 \%}$ & $\begin{array}{c}\text { Avg. } \\
\text { porosity }\end{array}$ \\
\hline & & & $\mathbf{c m}^{3} \mathrm{~cm}^{-3}$ & & & $\mathrm{~cm}^{3} \mathrm{~cm}^{-}$ \\
\hline Sand & 436.8 & 408.0 & 0.44 & 218.4 & 369.6 & 0.39 \\
\hline Fine sand & 338.4 & 283.2 & 0.4 & 240.0 & 364.8 & 0.39 \\
\hline Loamy sand & 295.2 & 266.4 & 0.45 & 98.4 & 110.4 & 0.37 \\
\hline $\begin{array}{l}\text { Loamy fine } \\
\text { sand }\end{array}$ & 148.8 & 206.4 & 0.46 & 28.8 & 261.6 & $\mathbf{0 . 3 7}$ \\
\hline Sandy loam & 134.4 & 240 & & 31.2 & & 0.37 \\
\hline $\begin{array}{l}\text { Fine sandy } \\
\text { loam }\end{array}$ & 52.8 & 62.4 & 0.45 & 19.7 & 32.6 & 0.36 \\
\hline Loam & 9.4 & 63.4 & 0.47 & 14.9 & 32.9 & 0.39 \\
\hline Silt loam & 34.6 & 70.8 & & 8.2 & 21.4 & 0.39 \\
\hline $\begin{array}{l}\text { Sandy clay } \\
\text { loam }\end{array}$ & 18.5 & 116.4 & 0.44 & 6.7 & 23.8 & 0.37 \\
\hline Clay loam & 10.1 & 26.1 & 0.48 & 1.7 & 8.6 & 0.4 \\
\hline $\begin{array}{l}\text { Silty clay } \\
\text { loam }\end{array}$ & 8.9 & 19.5 & 0.5 & 11.8 & 28.1 & 0.43 \\
\hline Clay & 4.8 & 12.2 & 0.48 & 4.3 & 15.9 & 0.4 \\
\hline
\end{tabular}

able at the site. We intended to use PTFs developed from large (>200 samples) databases. To estimate soil water retention, we selected 22 PTFs developed in different regions. The PTFs are listed in the Appendix A. ${ }^{1}$ Six of the PTFs estimated parameters of the Brooks-Corey equation (Brooks and Corey, 1964):

$$
\frac{\theta-\theta_{\mathrm{r}}}{\phi-\theta_{\mathrm{r}}}=\left\{\begin{array}{cl}
\left(\frac{h_{\mathrm{b}}}{h}\right)^{\lambda}, & h>h_{\mathrm{b}} \\
1, & h \leq h_{\mathrm{b}}
\end{array}\right.
$$

and five other equations estimated parameters of the van Genuchten Eq. [1]. In Eq. [2], $\phi$ is the porosity, $h_{\mathrm{b}}$ is bubbling pressure, $\lambda$ is pore size distribution index. Ten more PTFs estimated the water contents at several fixed capillary pressures. The van Genuchten parameters $\theta_{\mathrm{s}}, \theta_{\mathrm{r}}, \alpha$, and $n$ of Eq. [1] were evaluated by fitting to the water retention points obtained from those PTF equations. The value of parameter $m$ was calculated as $m=1-1 / n$. The residual water content $\theta_{\mathrm{r}}$ was set to $0.001 \mathrm{~cm}^{3} \mathrm{~cm}^{-3}$, and the saturated water content $\theta_{\mathrm{s}}$ was set equal to the porosity for PTFs that evaluated values of water content at two capillary pressures $(330$ and $15000 \mathrm{~cm})$. Two PTFs (Vereecken et al., 1989; Varallyay et al., 1982) evaluated van Genuchten parameters in Eq. [1] assuming $m=1$. To use these PTFs for the water flow simulations, water contents were calculated at capillary pressures used by those authors to derive their PTFs. The van Genuchten parameters

${ }^{1}$ A FORTRAN code to estimate water retention with PTFs of this work is available on request from the corresponding author. $\theta_{\mathrm{s}}, \theta_{\mathrm{r}}, \alpha$, and $n$ were evaluated by fitting Eq. [1] to the water retention points assuming $m=1-1 / n$. We also used the Rosetta software (Schaap, 2004) to generate van Genuchten parameters from texture and bulk density.

We could find only two PTFs to estimate soil hydraulic conductivity that were developed and/or tested with large databases (Rawls et al., 1998; Wösten et al., 1999). Since the ensemble prediction method did not seem feasible with only two PTFs, we used the PTF developed by Rawls et al. (1998), which gave estimates of the median and the difference between values corresponding to 25 and $75 \%$ probability levels (Table 3). This PTF hence could be used in principle to generate random values of the saturated hydraulic conductivity.

\section{Multimodel Ensemble Prediction of Soil Water Flow}

The HYDRUS-1D software (Simunek et al., 1998) was used for the simulations. This software gives options to run simulations either with the van Genuchten water retention Eq. [1] or with the Brooks-Corey Eq. [2]. This option was selected depending on the pedotransfer function. The unsaturated hydraulic conductivity was calculated with the model of van Genuchten-Mualem (1980):

$$
K(h)=K_{\mathrm{s}} S_{\mathrm{e}}^{0.5}\left[1-\left(1-S_{\mathrm{e}}^{1 / m}\right)^{m}\right]^{2} S_{\mathrm{e}}=\frac{\theta-\theta_{\mathrm{r}}}{\theta_{\mathrm{s}}-\theta_{\mathrm{r}}}
$$

or with the model of Brooks and Corey (1964):

$$
K(h)=K_{\mathrm{s}} S_{\mathrm{e}}^{2 / \lambda}+2.5
$$

The multimodel ensemble prediction of soil water flow was performed by generating parameters with each of 22 PTFs for a separate simulation run. Water retention was estimated from the PTFs for individual layers (i.e., 0-25, 25-45, 45-65, 65-85, and $85-150 \mathrm{~cm}$; Table 1 ).

Another 60 simulations of soil water dynamics were made using parameters of the van Genuchten Eq. [1] and Genuchten-Mualem Eq. [3] obtained from the laboratory water retention measurements. Each simulation corresponded to the soil profile at one of the 60 locations. Median values of $K_{\mathrm{s}}$ distributions from Table 3 were used for the loam and silt loam texture classes at depth ranges 0 to 65 and 65 to $105 \mathrm{~cm}$, respectively, for simulations with both PTF-estimated and laboratory-measured water retention data.

All simulations of the soil water regime were done for the precipitation data shown in Fig. 1. Five periods without precipitation were selected to evaluate values of evaporation. Vertical soil water fluxes were calculated for each period using the mass conservation equation and Darcy-Buckingham Law. Estimated daily evaporation results are shown in Fig. 2. The variability in evaporation between periods was less than the variability within periods. A Kruskal-Wallis rank sum test

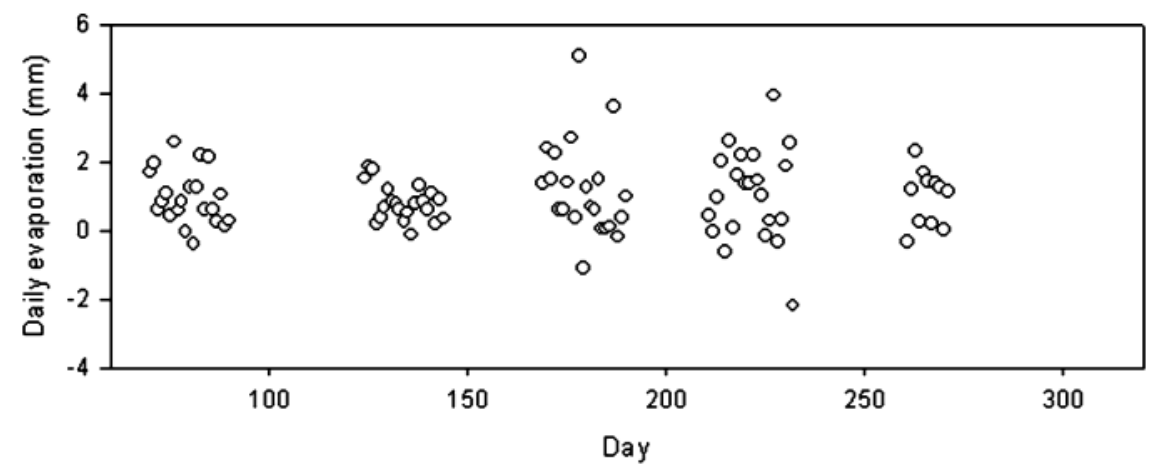

Fig. 2. Estimated daily evaporation rates for dry periods during the experiment. 
did not indicate a difference $(p=0.924)$ in mean daily evaporation values between periods, while an ANOVA test did not select the period as an influential factor at the 0.05 probability level. The evaporation rate at a probability level of $50 \%$ was $0.86 \mathrm{~mm} \mathrm{~d}^{-1}$. This value was included in the surface boundary condition. A free drainage condition was used at the lower boundary, assumed to be at a depth of $150 \mathrm{~cm}$. Values of the water content at measurement depths of $15,35,55,75$, and $95 \mathrm{~cm}$ were used as the initial condition across the 0 - to 25-, 25- to 45-, 45- to 65-, 65- to 85-, and 85- to $150-\mathrm{cm}$ soil layers, respectively.

Simulated soil water contents and soil water fluxes were compared with measured values at the trench scale. Average measured across-trench soil water contents were estimated at five measurement depths, with corrections for missing data as described in (Pachepsky et al., 2005a, 2005b). Simulated water fluxes at depths of 15 and $55 \mathrm{~cm}$ were compared with fluxes measured with passive capillary lysimeters. Simulated water fluxes at the depth of $105 \mathrm{~cm}$ were compared with flux values estimated at this depth from daily mass balance computations assuming that water contents measured at depths of $15,35,55$,
75 , and $95 \mathrm{~cm}$ are representative across 0 - to $25-, 25$ - to $45-, 45-$ to $65-, 65-$ to $85-$, and $85-$ to $150-\mathrm{cm}$ soil layers, respectively.

\section{RESULTS}

\section{Soil Water Contents}

Simulated water contents are compared with measured values in Fig. 3 and Fig. 4. Using the laboratory-measured water retention did lead to the relatively low accuracy (Fig. 3) with the simulated initial distributions of pressure heads deviating apparently far from the actual ones, while the first period of simulations was characterized by a substantial loss of water through the bottom of the profile. The simulations consistently underestimated measured soil water contents. The average difference between average simulated and average measured water contents varied with depth from -0.085 to $-0.149 \mathrm{~cm}^{3} \mathrm{~cm}^{-3}$. The minimum average error was obtained for a depth of $15 \mathrm{~cm}$, and maximum error at $55 \mathrm{~cm}$. The RMSE was $0.086 \mathrm{~cm}^{3}$

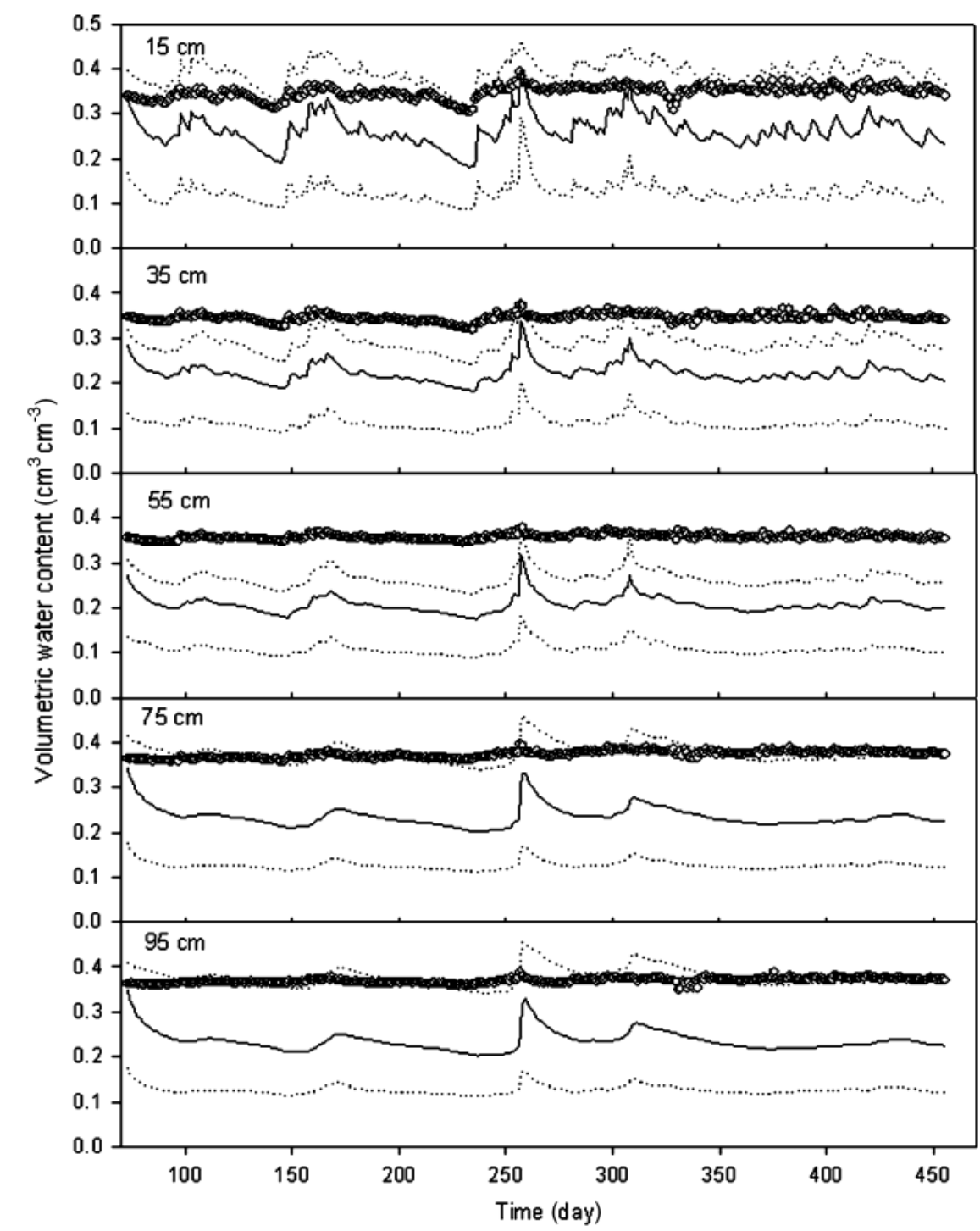

Fig. 3. Average field-measured water content data at several depths (symbols) and simulated results obtained with the laboratory water retention data (lines). Solid line is the median value; dotted lines are the $95 \%$ tolerance interval. 


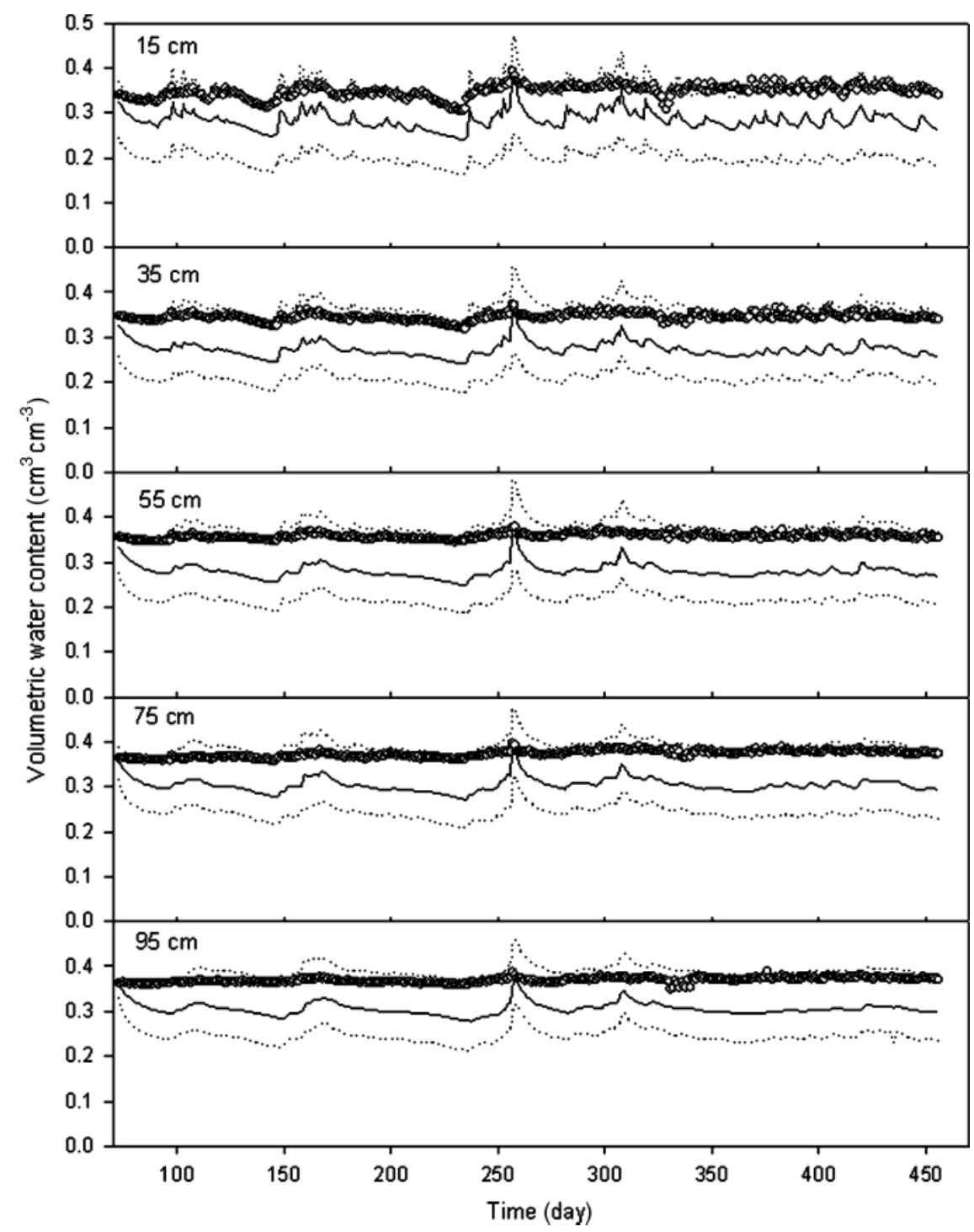

Fig. 4. Average field-measured water content data at several depths (symbols) and simulated results obtained with the pedotransfer function ensemble (lines). Solid line is the median value; dotted lines are the $95 \%$ tolerance interval.

$\mathrm{cm}^{-3}$ at the $15-\mathrm{cm}$ depth and varied between 0.12 and $0.15 \mathrm{~cm}^{3} \mathrm{~cm}^{-3}$ at larger depths.

Results of water content simulations with the ensemble of PTFs (Fig. 4) were qualitatively similar to those obtained with the laboratory water retention data (Fig. 3). However, the accuracy of PTF simulations was generally better than those using the laboratory data. The average difference between the simulated and measured water contents was $-0.068 \mathrm{~cm}^{3} \mathrm{~cm}^{-3}$. Measured water contents were mostly within the $95 \%$ tolerance interval of simulated values. The median simulated water contents were less than field-measured values, much like for the simulations using the laboratory-measured water retention data. The range in the average error of the predicted water contents was less compared with the simulations using the laboratory-measured water retention data. The values error was in the range from -0.062 to $-0.076 \mathrm{~cm}^{3} \mathrm{~cm}^{-3}$. The minimum average error was obtained at depths of 15 and $95 \mathrm{~cm}$, while maximum error occurred at depth of
$55 \mathrm{~cm}$. The RMSE was between 0.062 and $0.072 \mathrm{~cm}^{3} \mathrm{~cm}^{-3}$. No relationship between the errors of simulation and values of measured water content were found either for the laboratory-measured or PFT ensemble estimated water retention data.

The uncertainty in simulated water contents varied with depth. The maximum width of the $95 \%$ tolerance interval was found at a depth of $15 \mathrm{~cm}$ using the laboratory water retention data and at a depth of $55 \mathrm{~cm}$ for the ensemblepredicted water retention estimates. The narrowest tolerance interval occurred at a depth of $55 \mathrm{~cm}$ using laboratory water retention data and at a depth of $95 \mathrm{~cm}$ using the ensemble-predicted water retention information. In general, the uncertainty in simulated water contents was higher with the laboratory data, which resulted in tolerance intervals that were 1.14 to 1.79 times wider than the ensemble-predicted water retention estimates.

A comparison of the statistical distributions of the RMSEs obtained in simulations with the laboratory data 


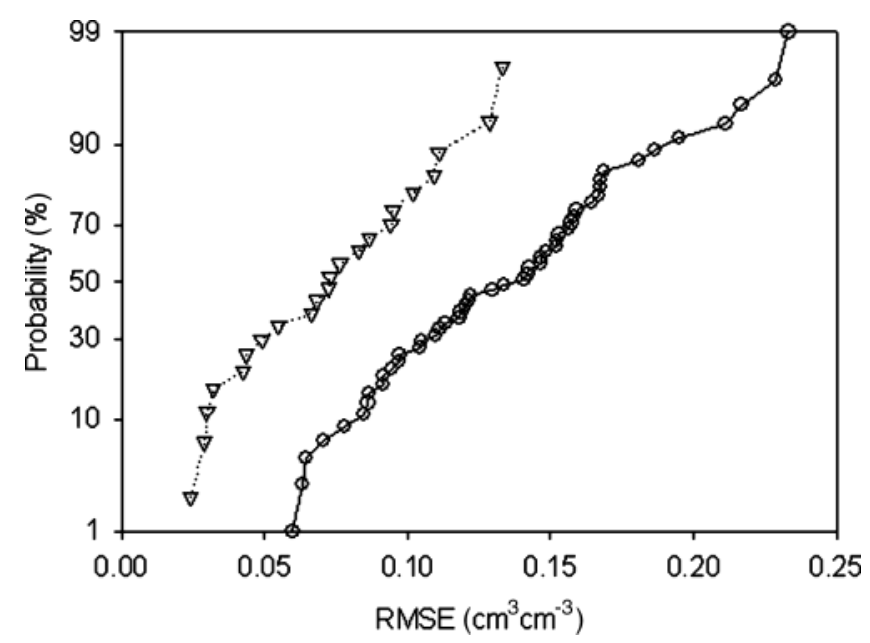

Fig. 5. Probability distributions of the RMSEs for soil water contents simulations using water retention data measured in the laboratory $(\bigcirc)$ and estimated with the pedotransfer function ensemble $(\nabla)$.

and with the PTFs supported the finding that the water content simulations with ensemble estimated water retention data was substantially better than using the laboratory data (Fig. 5). The graphs of the two probability distribution functions are parallel to each other, with the difference between them being about $0.062 \mathrm{~cm}^{3} \mathrm{~cm}^{-3}$.

\section{Comparison of Measured and Ensemble- Estimated Water Retention}

To find a possible explanation of the better simulation results with the PTF ensemble as compared with the "ensemble" of 60 soil columns using the laboratory water retention data, we compared both the laboratory and PTF-estimated water retention results with water retention data measured in the field. Results of this comparison are shown in Fig. 6. The ensemble estimation provided a better match with the field water retention data as compared with laboratory data. Boundaries of the $95 \%$ tolerance intervals for the ensemble estimates provided an envelope encompassing the field measurements (Fig. 6). A relatively few experimental field water retention points were outside the tolerance interval of the PTF ensemble. At the same time, how- ever, a substantial number of experimental field water retention points were outside the tolerance interval of the laboratory water retention data at a depth of $15 \mathrm{~cm}$, and especially at a depth of $95 \mathrm{~cm}$. In general, the field water retention data were closer to the middle section of the $95 \%$ tolerance interval of the PTF ensembleestimated water contents than to the middle section of the $95 \%$ tolerance interval of the laboratory data.

The uncertainty in ensemble-estimated water retention estimates was comparable to that in the laboratory estimates. The average ratio of the width of the tolerance intervals computed with the laboratory and ensemble-estimated water contents was 0.79 . This ratio varied from 0.24 to 3.19 , depending on the sampling depth and capillary pressure. Maximum differences in the tolerance interval widths between the ensemble and laboratory data were observed in the range of capillary pressure between 200 and $800 \mathrm{~cm}$ and for capillary pressure $<10 \mathrm{~cm}$. (Fig. 6). Laboratory measurements showed the ability of the soil to lose substantial amounts of water with changes in the capillary pressure from 100 to $1000 \mathrm{~cm}$, especially at the $15-$ and $95-\mathrm{cm}$ depths. The PTF ensemble predicted a more gradual loss of water during this drying process. The PTF ensemble also gave a much wider range of estimates of the water contents around the wilting point $(\approx 15000 \mathrm{~cm})$ as compared with the laboratory data.

\section{Performance of Individual Pedotransfer Functions}

Data on the accuracy of the simulations with individual PTFs are shown in Table 4. The differences between RMSEs in the water contents were substantial. A PTF ranking in terms of their RMSE values shows that the best results were obtained with PTFs derived from the all-USA database (Gupta and Larson, 1979) and the all-European database (Wösten et al., 1999).

\section{Effect of Saturated Hydraulic Conductivity Estimation}

Results of the simulations shown in Fig. 3 and 4 may be affected by the value of the saturated hydraulic conductivity. To assess this effect, we assumed lognormal

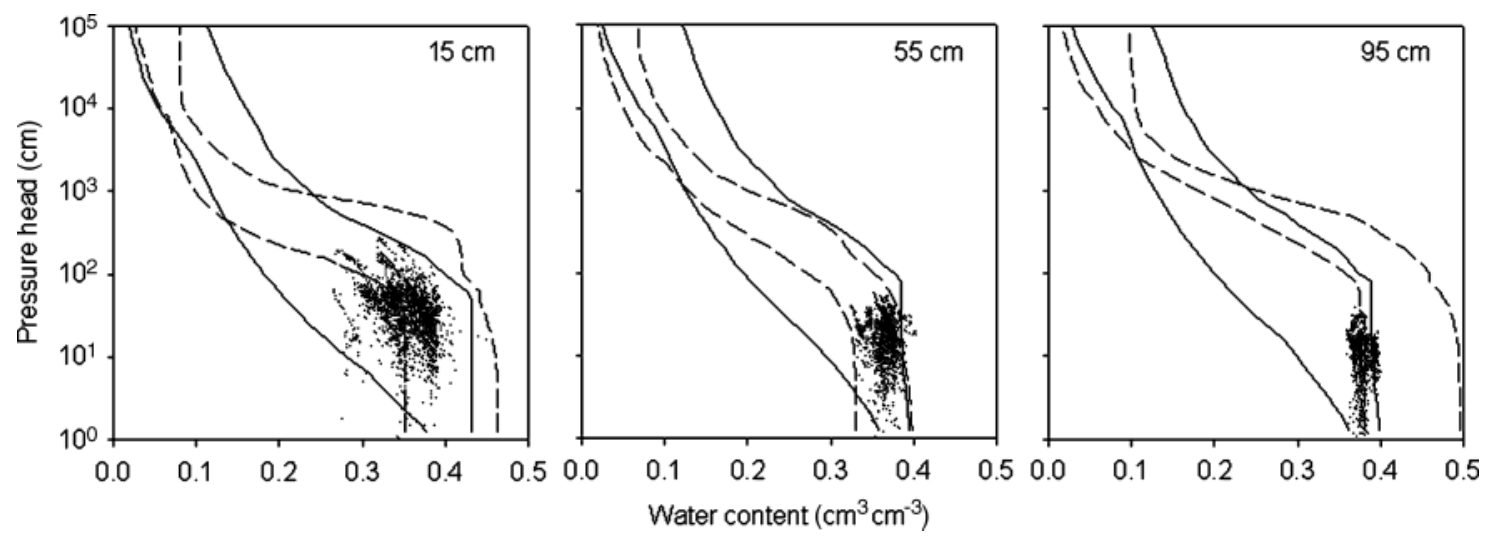

Fig. 6. Field-measured and estimated soil water retention curves along the trench. Dots are field measurements, dashed lines the 95\% tolerance interval of the laboratory water retention data, and solid lines the $95 \%$ tolerance interval of pedotransfer function ensemble-estimated water retention curve. 
Table 4. Root-mean-square errors of water contents in simulations with individual pedotransfer functions.

\begin{tabular}{|c|c|c|c|c|c|c|c|c|}
\hline \multirow{2}{*}{$\begin{array}{l}\text { Pedotransfer } \\
\text { function }\end{array}$} & \multirow[b]{2}{*}{ RMSE } & \multirow[b]{2}{*}{ Rank $\dagger$} & \multicolumn{6}{|c|}{ PTF predictors } \\
\hline & & & Clay & Silt & Sand & BD & $\mathbf{O M}$ & Itop \\
\hline & $\mathrm{cm}^{3} \mathrm{~cm}^{-3}$ & & & & & & & \\
\hline Baumer, 1992 & 0.044 & 6 & + & & + & + & + & \\
\hline Bruand et al., 1994 & 0.072 & 11 & + & & & & & \\
\hline $\begin{array}{l}\text { Campbell and } \\
\text { Shiosawa, } 1992\end{array}$ & 0.102 & 18 & + & & + & + & & \\
\hline Canarache, 1993 & 0.083 & 14 & + & & & + & & \\
\hline $\begin{array}{l}\text { Gupta and } \\
\text { Larson, } 1979\end{array}$ & 0.024 & 1 & + & + & + & + & + & \\
\hline Hall et al., 1977 & 0.030 & 3 & + & + & + & + & & \\
\hline Mayr and Jarvis, 1999 & 0.087 & 15 & + & + & + & + & + & \\
\hline $\begin{array}{l}\text { Oosterveld and } \\
\text { Chang, 1980 }\end{array}$ & 0.111 & 20 & + & & + & & & \\
\hline Peterson et al., 1968 & 0.032 & 4 & + & & & & & \\
\hline $\begin{array}{l}\text { Rajkai and } \\
\text { Varallyay, } 1992\end{array}$ & 0.129 & 21 & + & & + & + & + & \\
\hline Rawls et al., 1983 & 0.068 & 10 & + & + & + & + & + & \\
\hline $\begin{array}{l}\text { Rawls and } \\
\text { Brakensiek, } 1985\end{array}$ & 0.133 & 22 & + & & + & + & & \\
\hline Rawls et al., 1982 & 0.076 & 13 & + & + & + & + & & \\
\hline Rosetta & 0.109 & 19 & + & + & + & + & & \\
\hline Saxton et al., 1986 & 0.095 & 17 & + & & + & & & \\
\hline $\begin{array}{l}\text { Tomasella and } \\
\text { Hodnett, } 1998\end{array}$ & 0.042 & 5 & + & + & & & & \\
\hline Varallyay et al., 1982 & 0.066 & 9 & + & & & + & & + \\
\hline Vereecken et al., 1989 & 0.055 & 8 & + & & + & + & + & \\
\hline Williams et al., 1992 & 0.094 & 16 & + & & + & & + & \\
\hline Williams et al., 1992 & 0.073 & 12 & + & & + & + & & \\
\hline Wösten et al., 1999 & 0.049 & 7 & + & + & + & & & + \\
\hline Wösten et al., 1999 & 0.029 & 2 & + & + & + & + & + & + \\
\hline
\end{tabular}

$\dagger$ PTF ranked according the RMSE values; smallest rank corresponds to the smallest RMSE.

\$Variable equal zero for subsoil and one for topsoil.

distribution of the $K_{\mathrm{s}}$ values in Table 3 and performed Monte Carlo simulations of soil water flow with $K_{\mathrm{s}}$ randomly sampled from this lognormal distribution, and using fixed laboratory water retention data taken at the $50 \%$ probability. Figure 7 demonstrates that the effect of $K_{\mathrm{s}}$ on the simulation results can indeed be profound. The $95 \%$ tolerance interval of the simulated water contents was on average from 1.27 to 1.53 times wider when the water retention was varied as compared with simulations with variable $K_{\mathrm{s}}$. The difference was more pronounced at depths of 15 and $35 \mathrm{~cm}$. In $75 \%$ of cases, simulations with a variable $K_{\mathrm{s}}$ produced water content RMSE values that were smaller than for simulations with variable water retention data.

\section{Soil Water Fluxes}

The accuracy of soil water flux predictions using both the PTFs and the laboratory water retention data was evaluated over three wetting-drying periods (Days 112143, 144-232, and 233-275) that are visible in both the precipitation data (Fig. 1) and in the measured soil water content time series (Fig. 3 and 4). The accuracy was satisfactory (Fig. 8) for simulations with both the laboratory and PTF ensemble-estimated water retention data.

\section{Effect of the Time Scale}

To evaluate the ability of PTF models to estimate the soil water fluxes for shorter periods of time, we computed simulated and measured daily averages using time windows of $1,2,4,8,16$, and $32 \mathrm{~d}$. Some of our results are shown in Fig. 9. The error in the daily flux increased as the time window decreased. A well-defined scaling dependence of the error existed in the daily flux on the window size. The exponent was approximately -0.75 at the $15-$ and $105-\mathrm{cm}$ depths, but was smaller at the $55-\mathrm{cm}$ depth. However, the measurements at this depth $(55 \mathrm{~cm})$ showed a substantial scatter, while the average was never reproduced well (Fig. 9). The scaling hence may not depend on depth.

\section{DISCUSSION}

The accuracy of the water content simulations was higher when the ensemble of PTFs was used as compared with simulations with the laboratory-measured retention data (Fig. 3 and 4). This may be attributed to a better representation of water retention with the PTF ensemble as compared with the laboratory measurements (Fig. 6). This probably occurred because water retention was generally higher in the field than in the laboratory, while the ensemble predicted higher water retention. Such differences were previously also observed within a large dataset (Pachepsky et al., 2001) and were found to increase with an increase in clay content. The differences were attributed to the difference in measurement scales between the field and laboratory, and a scale dependence in the soil bulk density. The largest differences in our study were observed for the $\mathrm{C} 2$ horizon at the $90-$ to $95-\mathrm{cm}$ depth, where the clay content was the largest compared with other horizons. The ensemble prediction also produced a smaller initial loss of water from the profile due to the mismatch between simulated and actual capillary pressures.

The PTF ensemble provided more robust simulations. The tolerance interval of water contents simulated with the PTF ensemble prediction was found to be substantially smaller than with the laboratory water retention data (Fig. 3 and 4), in spite of the larger uncertainty in water retention estimated using the ensemble of PTFs, as compared with the laboratory data. No close relationship was found between the uncertainty in water retention and uncertainty in the simulated water contents. For example, the variability in laboratory water retention was similar at depths of 15 and $95 \mathrm{~cm}$ within the range of capillary pressures observed in the field. However, the variability in simulated water contents was two times smaller at the $95-\mathrm{cm}$ depth than at $15 \mathrm{~cm}$. At the same time, a similar variability in simulated water contents was found at depths of 15 and $55 \mathrm{~cm}$, although the laboratory water retention data were about two times more variable at $15 \mathrm{~cm}$ than at $55 \mathrm{~cm}$. We note that the variability in ensemble-predicted water retention was higher than the variability in laboratory-measured water retention. However, the difference in widths of the tolerance intervals was less than one would expect, mostly because the small-scale variability in water retention was relatively high (Fig. 6). Such variability at the core scale is not uncommon, and therefore a comparable variability in the ensemble water retention and the small-scale water retention data could be expected at other sites. 


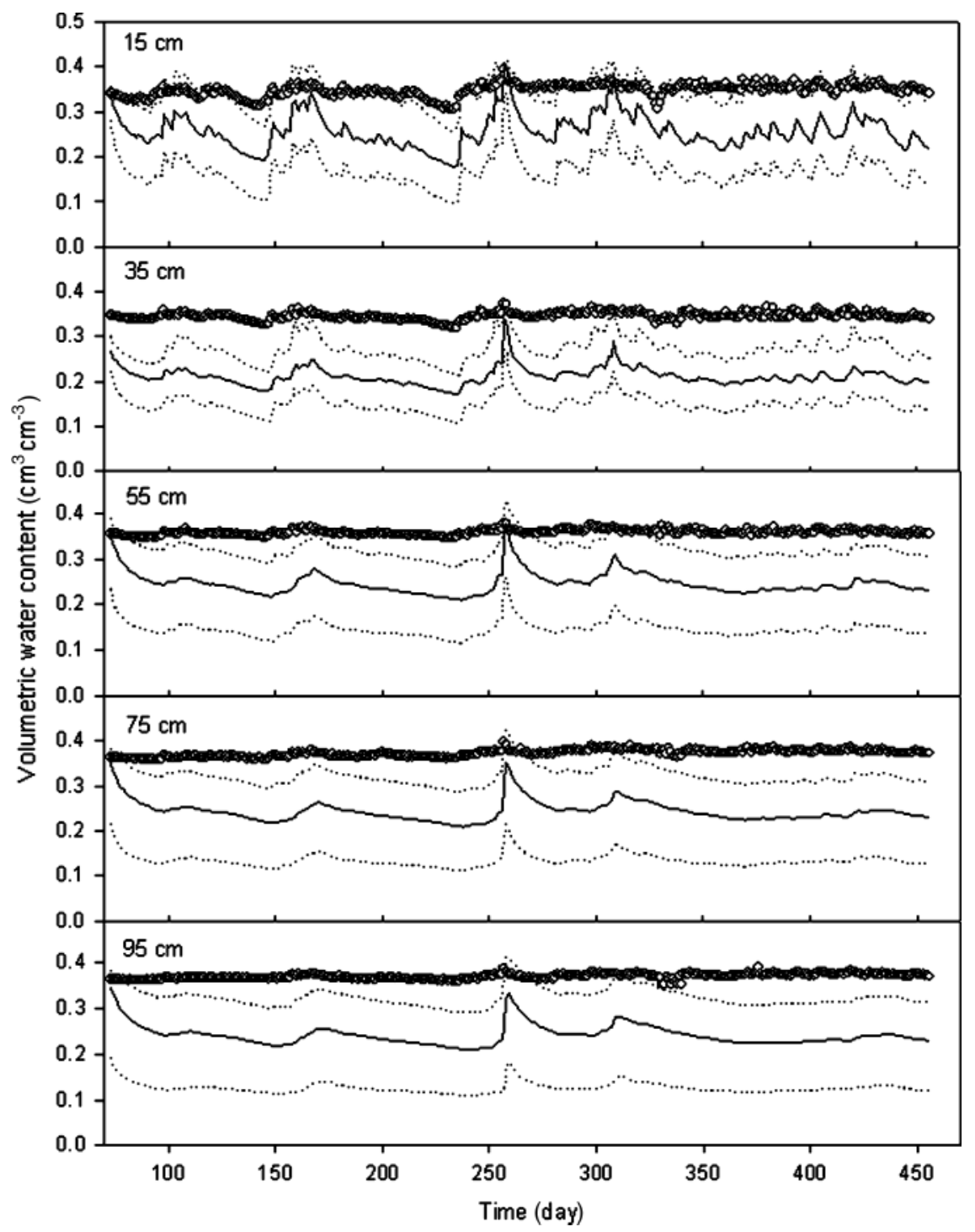

Fig. 7. Average field-measured water content data at several depths (symbols) and simulated results obtained with the random $K_{\mathrm{s}}$ and the laboratory water retention data having a $50 \%$ probability (lines). Solid line is the median value; dotted lines are the $95 \%$ tolerance interval.

Using the PTF ensemble is, in essence, the utilization of generic information available before the site study. Data in Fig. 6 show that such information inherently has considerable variability. The differences in accuracy of simulations with individual PTF (Table 4) are large and illustrate difficulties in selecting a single PTF for a specific site. Although the all-USA PTF of Gupta and Larson (1979) is ranked relatively high, other all-USA PTFs have relatively low ranks. The PTF developed for Belgian soils (Vereecken et al., 1989) was ranked eighth and provided only moderate accuracy with the Belgian dataset in this work compared with the all-European PTFs of Wösten et al. (1999), which had a rank of 2. Analysis of the data in Table 4 and the original publications did not allow us to explain why some PTFs performed better than others in our particular case.

We note that the variability in field water retention data was quite high in our study. Natural spatial variations in soil structure, soil water retention hysteresis, and a nonequilibrium state of the soil water system are among possible reasons for this. Neither the available PTFs nor typical draining measurements can account for field hysteresis and nonequilibrium in water retention. These possibilities, among other reasons, may cause errors in the soil water content simulations.

An ensemble of saturated hydraulic conductivity PTFs was not tested in this study. Far less literature exists on estimating $K_{\mathrm{s}}$ as compared with water retention (see, e.g., review by Pachepsky and Rawls, 2004). The effect of varying $K_{\mathrm{s}}$ within a realistic range was substantial (Fig. 7); this implies a need to emphasize measurement of the hydraulic conductivity in field campaigns to characterize the soil hydraulic properties.

The differences in accuracy of the various water content simulations did not manifest themselves in the simulated soil water fluxes (Fig. 8). The accuracy was similar at both large (Fig. 8) and small (Fig. 9) temporal scales. No statistically significant correlation was found between fluxes at small temporal scales simulated with the PTFs ensemble and the laboratory water retention 

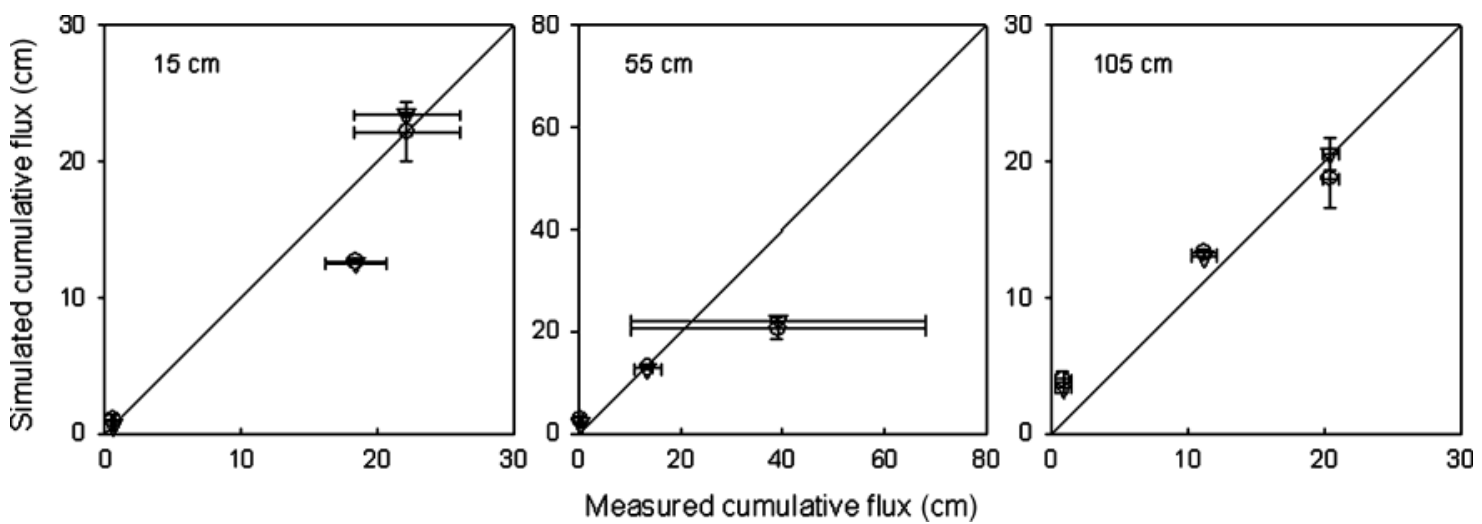

Fig. 8. Measured and simulated cumulative soil water fluxes for three wetting-drying periods (Days 112-143, 144-232, and 233-275). $\bigcirc$, simulated with laboratory-measured water retention; $\nabla$, simulated with the pedotransfer function ensemble. Error bars show standard deviations.

data (results not shown). The similarity in flux simulation errors shown in Fig. 9 did not stem from the similarity in fluxes. A possible reason for the error scaling in Fig. 9 could be a smoothing effect of a wick-imposed suction on the measured flux dynamics. Oscillations in soil water fluxes are probably better captured by simulations as compared with flow collected using passive capillary lysimeters.

Although predictions with a single PTF depend on the database used for the PTF development, an ensemble prediction will be less dependent on the individual PTFs if the number of individual PTFs is sufficient enough to represent natural variability in soil water retention. Predictions in meteorology often evaluate the uncertainty in multimodel predictions using both different models and the variability in predictions from each of those models. This approach, however, may have a limited applicability to the case of PTFs since the published information on the most PTFs is not sufficient to estimate the uncertainty envelope of the predictions. The technology for this has been introduced only recently (Schaap and
Leij, 1998), while most of the large-database PTFs were developed much earlier.

Simulations with the PTF ensemble were averaged without assigning any weights to the results from simulations with individual PTFs. Such weights can be assigned in applications where time series of the soil water content are measured, and where the accuracy of simulations with individual PTFs is known. Such assignment of weights has been used for multimodel predictions in meteorology (Hamill et al., 2005). This approach allows one to decrease the effect of an outlier (i.e., of a PTF that gives results completely inapplicable to the site in question). Another way to decrease the effect of outliers is to use the median predictions from the ensemble simulations instead of average values. The median and average predictions from the PTF ensemble simulations were very close in our study (results not shown).

The PTF ensemble was assembled somewhat arbitrarily in this work. Developing guidelines to compose such ensembles requires further research. For example, if a regional PTF is used in an ensemble with PTFs
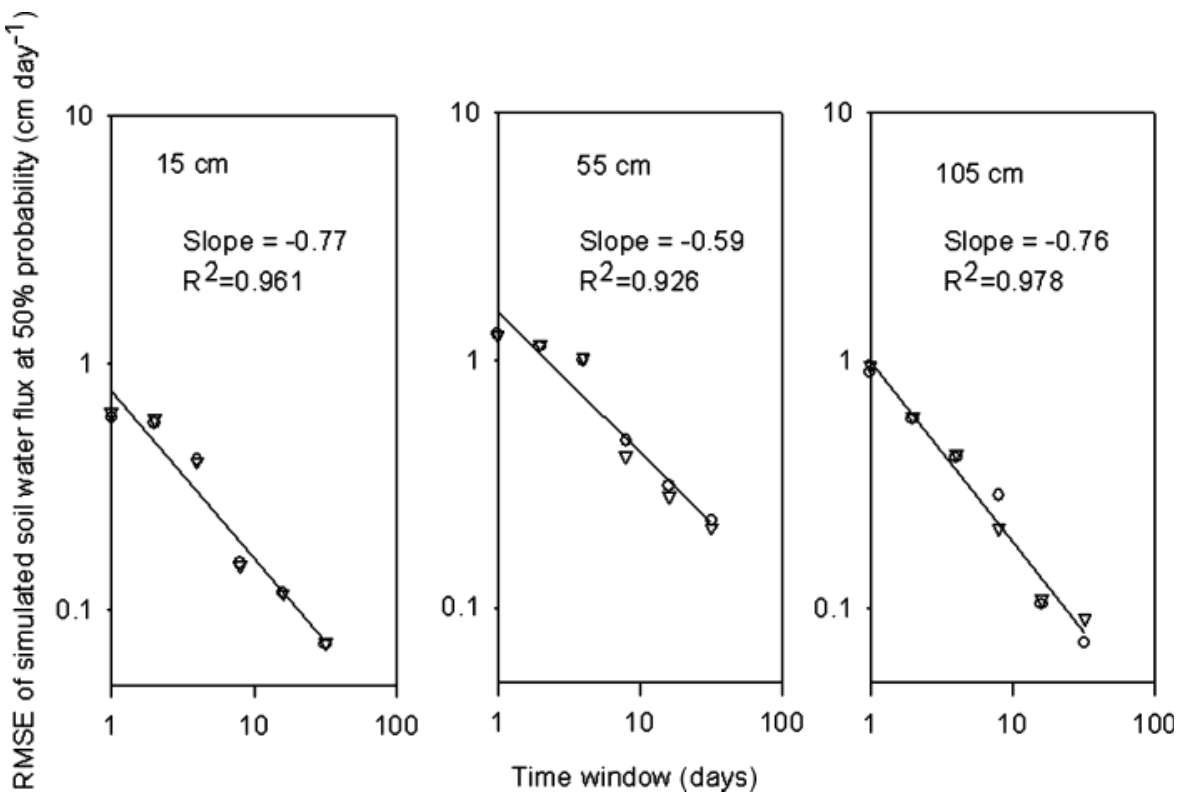

Fig. 9. Dependencies of average daily flux estimation error on time window over which fluxes were averaged. $\bigcirc$, simulated with laboratorymeasured water retention data; $\nabla$, simulated with the pedotransfer function ensemble. 
developed from a large database that included data from the same region, then those data may be weighted more heavily since they influence the ensemble results at least twice. Besides, large databases usually contain data that are obtained by a variety of methods. Perhaps this leads to a cancellation of errors compared with a PTF set derived using one specific method that may have a consistent bias when predicting specific soil water processes. More experiments with PTF ensembles are needed to decide on preferable attributes that have to be different between the ensemble elements (e.g., region, soil types, or landscape types).

As the ensemble prediction methodology is relatively young, the terms ensemble predictions and multimodel predictions are still often used with different meanings. While some researchers apply these terms to combining results from conceptually different models, others use them for averaging results from conceptually equivalent models developed on subsets of the large datasets and then averaging the results. For example, the method of "bagging" results of regression trees, which combines results from neural networks developed on subsets of the large dataset, is also referred to as an ensemble method (e.g., Opitz and Maclin, 1999). Even averaging of Monte Carlo simulations results is sometimes referred as an ensemble prediction. In general, ensemble modeling finds applications in disciplines where the object complexity is high, measurements are difficult, and where many conceptually different models hence may provide the same level of accuracy when developed and tested on different datasets or on different subsets of the same database. The fact that ensemble predictions are more accurate than individual models is something that is now supported by more and more empirical evidence.

Overall, the uncertainty in the ensemble-estimated water retention estimates (as quantified by the width of the $95 \%$ tolerance interval of the water content at a specific pressure head) was comparable with the uncertainty in the laboratory water retention data. The PTF ensemble estimation gave substantially better approximations of field water retention compared with the laboratory data. Simulations of the soil water regime were performed using the HYDRUS-1D software with the laboratory-measured water retention at 60 locations of the trench and with the ensemble of PTF-estimated water retention data. Simulations with the PTFs ensemble produced, on average, two times smaller errors compared with laboratory data. The accuracy of simulating cumulative soil water fluxes did not differ between simulations with the laboratory-measured data and the PTF ensemble water retention estimates. We conclude that the ensemble prediction methodology is a promising approach for estimating hydraulic properties within an uncertainty context.

\section{APPENDIX}

\section{Pedotransfer Functions to Estimate Soil Water Retention}

In the equations below, the symbols $w$ and $\theta$ denote gravimetric $\left(\mathrm{g} \mathrm{g}^{-1}\right)$ and volumetric $\left(\mathrm{cm}^{3} \mathrm{~cm}^{-3}\right)$ water contents, re-
Table A1. Coefficients in the PTF of Rawls et al. (1982) $\theta=a+$ $b(\%$ sand $)+c(\%$ silt $)+d(\%$ clay $)+e(\%$ OM $)$ to predict volumetric soil water content at specific capillary pressure.

\begin{tabular}{lcclcc}
\hline Pressure head & \multicolumn{1}{c}{$\boldsymbol{a}$} & $\boldsymbol{b}$ & \multicolumn{1}{c}{$\boldsymbol{c}$} & $\boldsymbol{d}$ & $\boldsymbol{e}$ \\
\hline $\mathbf{k P a}$ & & & & & \\
$-\mathbf{1 0}$ & $\mathbf{0 . 4 1 1 8}$ & $-\mathbf{0 . 0 0 3 0}$ & $\mathbf{0}$ & $\mathbf{0 . 0 0 2 3}$ & $\mathbf{0 . 0 3 1 7}$ \\
$-\mathbf{2 0}$ & $\mathbf{0 . 3 1 2 1}$ & $-\mathbf{0 . 0 0 2 4}$ & $\mathbf{0}$ & $\mathbf{0 . 0 0 3 2}$ & $\mathbf{0 . 0 3 1 4}$ \\
$-\mathbf{3 3}$ & $\mathbf{0 . 2 5 7 6}$ & $-\mathbf{0 . 0 0 2 0}$ & $\mathbf{0}$ & $\mathbf{0 . 0 0 3 6}$ & $\mathbf{0 . 0 2 9 9}$ \\
$-\mathbf{6 0}$ & $\mathbf{0 . 2 0 6 5}$ & $-\mathbf{0 . 0 0 1 6}$ & $\mathbf{0}$ & $\mathbf{0 . 0 0 4 0}$ & $\mathbf{0 . 0 2 7 5}$ \\
$-\mathbf{1 0 0}$ & $\mathbf{0 . 0 3 4 9}$ & $\mathbf{0}$ & $\mathbf{0 . 0 0 1 4}$ & $\mathbf{0 . 0 0 5 5}$ & $\mathbf{0 . 0 2 5 1}$ \\
$-\mathbf{2 0 0}$ & $\mathbf{0 . 0 2 8 1}$ & $\mathbf{0}$ & $\mathbf{0 . 0 0 1 1}$ & $\mathbf{0 . 0 0 5 4}$ & $\mathbf{0 . 0 2 0 0}$ \\
$-\mathbf{4 0 0}$ & $\mathbf{0 . 0 2 3 8}$ & $\mathbf{0}$ & $\mathbf{0 . 0 0 0 8}$ & $\mathbf{0 . 0 0 5 2}$ & $\mathbf{0 . 0 1 9 0}$ \\
$-\mathbf{7 0 0}$ & $\mathbf{0 . 0 2 1 6}$ & $\mathbf{0}$ & $\mathbf{0 . 0 0 0 6}$ & $\mathbf{0 . 0 0 5 0}$ & $\mathbf{0 . 0 1 6 7}$ \\
$-\mathbf{1 0 0 0}$ & $\mathbf{0 . 0 2 0 5}$ & $\mathbf{0}$ & $\mathbf{0 . 0 0 0 5}$ & $\mathbf{0 . 0 0 4 9}$ & $\mathbf{0 . 0 1 5 4}$ \\
$-\mathbf{1 5 0 0}$ & $\mathbf{0 . 0 2 6 0}$ & $\mathbf{0}$ & $\mathbf{0}$ & $\mathbf{0 . 0 0 5 0}$ & $\mathbf{0 . 0 1 5 8}$ \\
\hline
\end{tabular}

spectively; the subscripts 330 and 15000 indicate the capillary pressures $(\mathrm{cm})$. Clay and sand denote percentages of textural fractions according the USDA textural classification. OM is the organic matter content (\%), OC is the organic $\mathrm{C}$ content $(\%), \rho_{\mathrm{b}}$ is the bulk density $\left(\mathrm{g} \mathrm{cm}^{-3}\right)$, and the other symbols are defined as they appear.

\section{Equations for Estimating the Soil Water Content at Fixed Capillary Pressures}

Rawls et al. (1982) used the U.S. Cooperative Soil Survey Database to develop 12 regression equations to relate the soil water contents at 10 capillary pressures to sand, clay, and organic matter contents (Table A1). A similar set of equations was later developed to use knowledge of the bulk density along with the sand, clay and organic matter contents (Rawls et al., 1982; Table A2).

Baumer (1992) used the U.S. National Soil Survey database to predict the gravimetric water content at capillary pressures of $15000 \mathrm{~cm}$ and $330 \mathrm{~cm}$ with the equations:

$$
\begin{aligned}
w_{15000}= & 0.01 \rho_{\mathrm{b}}(0.71+0.45 \mathrm{OM}+0.336 \text { clay } \\
& \left.+0.117 \text { clay }\left(\mathrm{CA}^{3 / 2}\right)+0.004 \text { claySAR }\right) \\
w_{330}= & 0.01 \rho_{\mathrm{b}}\left(15.84+0.746 \mathrm{OM}+2.2025 \mathrm{CA}^{2}\right. \\
& \left.-0.137 \text { sand }+0.743 w_{15000}\right) \text { if clay }>10 \% \\
w_{330}= & 0.01 \rho_{\mathrm{b}}\left(15.84+0.746 \mathrm{OM}+0.02 \mathrm{CA}^{2} \text { clay }^{2}\right. \\
& \left.-0.137 \text { sand }+0.743 w_{15000}\right) \text { if clay } \leq 10 \%
\end{aligned}
$$

Table A2. Coefficients in the PTF of Rawls et al. (1983) $\theta=a+$ $b(\%$ sand $)+c(\%$ clay $)+d(\%$ OM $)+e \rho_{\mathrm{b}}$ to predict the volumetric soil water content $\theta\left(\mathrm{cm}^{3} \mathrm{~cm}^{-3}\right)$ at specific capillary pressure from soil texture, organic matter content and soil bulk density $\left(\mathrm{g} \mathrm{cm}^{-3}\right)$.

\begin{tabular}{lccccc}
\hline Pressure head & $\boldsymbol{a}$ & $\boldsymbol{b}$ & $\boldsymbol{c}$ & $\boldsymbol{d}$ & $\boldsymbol{e}$ \\
\hline $\mathbf{c m}$ & & & & & \\
$-\mathbf{2 0 0}$ & $\mathbf{0 . 4 1 8 0}$ & $-\mathbf{0 . 0 0 2 1}$ & $\mathbf{0 . 0 0 3 5}$ & $\mathbf{0 . 0 2 3 2}$ & $-\mathbf{0 . 0 8 5 9}$ \\
$-\mathbf{3 3 0}$ & $\mathbf{0 . 3 4 8 6}$ & $-\mathbf{0 . 0 0 1 8}$ & $\mathbf{0 . 0 0 3 9}$ & $\mathbf{0 . 0 2 2 8}$ & $-\mathbf{0 . 0 7 3 8}$ \\
$-\mathbf{6 0 0}$ & $\mathbf{0 . 2 8 1 9}$ & $-\mathbf{0 . 0 0 1 4}$ & $\mathbf{0 . 0 0 4 2}$ & $\mathbf{0 . 0 2 1 6}$ & $-\mathbf{0 . 0 6 1 2}$ \\
$-\mathbf{1 0 0 0}$ & $\mathbf{0 . 2 3 5 2}$ & $-\mathbf{0 . 0 0 1 2}$ & $\mathbf{0 . 0 0 4 3}$ & $\mathbf{0 . 0 2 0 2}$ & $-\mathbf{0 . 0 5 1 7}$ \\
$-\mathbf{2 0 0 0}$ & $\mathbf{0 . 1 8 3 7}$ & $-\mathbf{0 . 0 0 0 9}$ & $\mathbf{0 . 0 0 4 4}$ & $\mathbf{0 . 0 1 8 1}$ & $-\mathbf{0 . 0 4 0 7}$ \\
$-\mathbf{4 0 0 0}$ & $\mathbf{0 . 1 4 2 6}$ & $-\mathbf{0 . 0 0 0 7}$ & $\mathbf{0 . 0 0 4 5}$ & $\mathbf{0 . 0 1 6 0}$ & $-\mathbf{0 . 0 3 1 5}$ \\
$-\mathbf{7 0 0 0}$ & $\mathbf{0 . 1 1 5 5}$ & $-\mathbf{0 . 0 0 0 5}$ & $\mathbf{0 . 0 0 4 5}$ & $\mathbf{0 . 0 1 4 3}$ & $-\mathbf{0 . 0 2 5 3}$ \\
$-\mathbf{1 0 0 0 0}$ & $\mathbf{0 . 1 0 0 5}$ & $-\mathbf{0 . 0 0 0 4}$ & $\mathbf{0 . 0 0 4 5}$ & $\mathbf{0 . 0 1 3 3}$ & $-\mathbf{0 . 0 2 1 8}$ \\
$-\mathbf{1 5 0 0 0}$ & $\mathbf{0 . 0 8 5 4}$ & $-\mathbf{0 . 0 0 0 4}$ & $\mathbf{0 . 0 0 4 4}$ & $\mathbf{0 . 0 1 2 2}$ & $-\mathbf{0 . 0 1 8 2}$ \\
\hline
\end{tabular}


where CA is the clay activity (i.e., the ratio of the cation exchange capacity of the mineral fraction to the clay content, $\mathrm{mol}_{\mathrm{c}} \mathrm{kg}^{-1}$ ), and SAR is the sodium adsorption ratio.

Bruand et al. (1994) estimated the volumetric water content at capillary pressures of 15000 and $330 \mathrm{~cm}$ as

$$
\theta_{15000}=(0.008+0.00367 \text { clay }) /(0.471+0.00411 \text { clay })
$$

$$
\theta_{330}=(0.043+0.004 \text { clay }) /(0.471+0.00411 \text { clay })
$$

Canarache (1993) applied regression analysis to the Romanian national database to obtain the predictive equations:

$$
\begin{aligned}
\theta_{15000}= & 0.01 \rho_{\mathrm{b}}\left(0.2805 \text { clay }+0.0009615 \text { clay }^{2}\right) \\
\theta_{330}= & 0.01 \rho_{\mathrm{b}}\left(2.65+1.105 \text { clay }-0.01896 \text { clay }^{2}\right. \\
& +0.0001678 \text { clay }^{3}+15.12 \rho_{\mathrm{b}}-6.745 \rho_{\mathrm{b}}^{2} \\
& -0.1975{\text { clay } \left.\rho_{\mathrm{b}}\right)}
\end{aligned}
$$

Gupta and Larson (1979) used a subset of the U.S. National Cooperative Survey database to derive predictive equations for the volumetric water content at capillary pressures of 15000 and $330 \mathrm{~cm}$ as follows:

$$
\begin{aligned}
\theta_{330}= & 0.003075 \text { sand }+0.005886 \text { silt }+0.008039 \text { clay } \\
& +0.0022080 \mathrm{M}-0.1434 \rho_{\mathrm{b}} \\
\theta_{15000}= & 0.000059 \text { sand }+0.001142 \text { silt }+0.005766 \text { clay } \\
& +0.002280 \mathrm{M}+0.02671 \rho_{\mathrm{b}}
\end{aligned}
$$

Hall et al. (1977) analyzed a subset of British Soil Survey data and derived the equations

$$
\theta_{330}=0.01\left(20.81+0.45 \text { clay }+0.13 \text { silt }-5.95 \rho_{\mathrm{b}}\right)
$$

$$
\theta_{15000}=0.01\left(1.48+0.84 \text { clay }-0.0055 \text { clay }^{2}\right)
$$

Petersen et al. (1968) worked with the Pennsylvania soil database. Their equations are:

$$
\begin{aligned}
\theta_{330} & =0.01\left(11.83+0.96 \text { clay }-0.008 \text { clay }^{2}\right) \\
\theta_{15000} & =0.01\left(1.74+0.76 \text { clay }-0.005 \text { clay }^{2}\right)
\end{aligned}
$$

Rajkai and Várallyay (1992) analyzed the Hungarian national database to obtain:

$$
\begin{gathered}
\theta_{330}=0.01\left[38.62-0.00479 \text { sand }-0.0019(\mathrm{sand} / \mathrm{silt})^{2}\right] \\
\theta_{15000}=0.01\left(1.39+0.36 \text { clay }+0.22 \mathrm{OM}^{2}\right)
\end{gathered}
$$

In our study we used clay content instead of the unavailable fine fraction content in Eq. [A15].

Tomasella and Hodnett (1998) studied Brazilian soils and derived the equations:

$$
\begin{aligned}
\theta_{330} & =0.01(4.046+0.426 \text { silt }+0.404 \text { clay }) \\
\theta_{15000} & =0.01(0.91+0.150 \text { silt }+0.396 \text { clay })
\end{aligned}
$$

\section{Equations to Estimate Brooks-Corey Parameters}

Rawls and Brakensiek (1985) developed the following equations to estimate the Brooks-Corey parameters in Eq. [1]:

$$
\begin{aligned}
h_{\mathrm{b}}= & \exp \left(5.340+0.185 \text { clay }-2.484 \phi-0.002 \text { clay }^{2}\right. \\
& -0.044 \text { sand } \phi+0.001 \text { sand }^{2} \phi^{2}-0.009 \text { clay }^{2} \phi^{2} \\
& -0.00001 \text { sand }{ }^{2} \text { clay }+0.009 \text { clay }^{2} \text { sand } \\
& \left.-0.0007 \text { sand }^{2} \phi+0.000005 \text { clay }^{2} \text { sand }-0.500 \phi^{2} \text { clay }\right)
\end{aligned}
$$

$$
\begin{aligned}
\lambda= & \exp \left(-0.784+0.018 \text { sand }-1.062 \phi-0.00005 \mathrm{sand}^{2}\right. \\
& -0.003 \text { clay }^{2}+1.111 \phi^{2}-0.031 \text { sand } \phi \\
& +0.0003 \text { sand }^{2} \phi^{2}-0.006 \text { clay }^{2} \phi^{2} \\
& \left.-0.000002 \text { sand }^{2} \text { clay }+0.008 \text { clay }^{2} \phi-0.007 \phi^{2} \text { clay }\right) \\
\theta_{\mathrm{r}}= & -0.018+0.0009 \text { sand }+0.005 \text { clay }+0.029 \phi \\
& -0.0002 \text { clay }^{2}-0.001 \text { sand } \phi-0.0002 \text { clay }^{2} \phi^{2} \\
& +0.0003 \text { clay }^{2} \phi-0.002 \phi^{2} \text { clay }
\end{aligned}
$$

Campbell and Shiozawa (1992) set the value of the residual water content in Eq. [2] equal to zero to transform the BrooksCorey model to:

$$
h=h_{\mathrm{b}}\left(\theta / \theta_{\mathrm{s}}\right)^{-b}
$$

The parameters in (A21), estimated from two data sets for British soils, were found to be

$$
\begin{aligned}
h_{\mathrm{es}} & =-0.05 d_{\mathrm{g}}^{-1 / 2} \\
b & =-20 h_{\mathrm{es}}+0.2 \sigma_{\mathrm{g}}
\end{aligned}
$$

where the value of $h_{\mathrm{es}}$ corresponds to the air entry pressure at a standard bulk density, $\rho_{\mathrm{b}}$ of $1.3 \mathrm{~g} \mathrm{~cm}^{-3}$. The proposed adjustment for bulk density is

$$
h_{\mathrm{b}}=h_{\mathrm{es}}\left(\rho_{\mathrm{b}} / 1.3\right)^{0.67 b}
$$

The geometric mean diameter $d_{\mathrm{g}}$ and geometric standard deviation are given by

$$
\begin{aligned}
& d_{\mathrm{g}}=\exp (-0.025-0.0363 \text { silt }-0.0688 \text { clay }) \\
& \sigma_{\mathrm{g}}=\exp \left(0.133 \text { silt }+0.477 \text { clay }-\ln ^{2} d_{\mathrm{g}}\right)^{1 / 2}
\end{aligned}
$$

Saxton et al. (1986) also set the value of the residual water content in Eq. [2] equal to zero and transformed the equation to

$$
h=A \theta^{B}
$$

where

$$
\begin{aligned}
A= & 100 \exp \left(-4.396-0.0715 \text { clay }-0.000488 \text { sand }^{2}\right. \\
& \left.-0.00004285 \text { sand }^{2} \text { clay }\right) \\
B= & -3.140-0.00222 \text { clay }^{2}-0.00003484 \text { sand }^{2} \text { clay }
\end{aligned}
$$

Oosterveld and Chang (1980) used a Canadian database and transformed Eq. [2] with $\theta_{\mathrm{r}}=0$ to the form

$$
\begin{aligned}
\theta= & 0.01 \rho_{\mathrm{b}}(35.367+0.644 \text { clay }-0.251 \text { sand } \\
& -0.045 D) h^{-0.190}
\end{aligned}
$$

where $D$ is the mean depth of the sample in centimeters. 
Williams et al. (1992) transformed Eq. [1] with $\theta_{r}=0$ to the logarithmic form

$$
\theta=A+B \ln h
$$

and applied it to an Australian database. Different pedotransfer equations were developed in their work for different types of available data of basic properties. The equations

$A=2.57+0.238 \ln$ (clay) -0.000192 sand $^{2}-0.0137$ sand

$$
-0.0926 \ln \mathrm{OM}+0.0412 \mathrm{OM}
$$

$B=-0.403+0.0871 \ln ($ clay $)-0.00077$ sand

were suggested when data on the organic matter are available, and the equations

$$
A=1.839+0.257 \ln (\text { clay })+0.3812-0.0001 \text { sand }^{2}
$$

$$
\begin{aligned}
B= & -0.303+0.093 \ln \left(\rho_{\mathrm{b}}\right)+0.0565 \ln (\text { clay }) \\
& -0.00003 \text { sand }^{2}
\end{aligned}
$$

for cases when no information about the organic matter content was available.

Mayr and Jarvis (1999) set $\theta_{\mathrm{r}}=0$ and porosity $\phi$ equal to the saturated water $\theta_{\mathrm{s}}$ in the Brooks-Corey equation and combined this equation for the dry range of soil water retention curve

$$
\theta=\theta_{\mathrm{s}}(h / a)^{-1 / b} \quad \theta<\theta_{i}
$$

with a parabolic equation for the wet range:

$$
\theta=\theta_{\mathrm{s}}-\frac{\theta_{\mathrm{s}} h^{2}\left(1-\theta_{i} / \theta_{\mathrm{s}}\right)}{a^{2}\left(\theta_{i} / \theta_{\mathrm{s}}\right)^{-2 b}} \quad \theta \geq \theta_{\mathrm{i}}
$$

The water content $\theta_{i}$ and the equivalent capillary pressure $h_{i}$ at the matching point are given by:

$$
\theta_{i}=\frac{2 b \theta_{\mathrm{s}}}{1+2 b}
$$

[A36]

and

$$
h_{i}=a\left(\frac{2 b}{1+2 b}\right)^{-b}
$$

Pedotransfer functions developed by Mayr and Jarvis (1999) from a Scandinavian dataset were:

$$
\begin{aligned}
& \log (a)=-4.9840297533+0.0509226283 \text { sand } \\
& +0.1575152771 \text { silt }+0.1240901644 \rho_{\mathrm{b}} \\
& -0.1640033143 \mathrm{OC}-0.0021767278 \text { silt }^{2} \\
& +0.0000143822 \mathrm{silt}^{3}+0.0008040715 \mathrm{clay}^{2} \\
& +0.0044067117 \mathrm{OC}^{2} \\
& +0.0092463819 \text { silt }-0.4542769707 \rho_{\mathrm{b}} \\
& -0.0497915563 \mathrm{OC}+0.0003294687 \mathrm{sand}^{2} \\
& +0.000001689056 \text { sand }^{3}+0.0011225373 \text { OC }^{2}
\end{aligned}
$$

$$
\begin{aligned}
\theta_{\mathrm{s}}= & 0.2345971971+0.0046614221 \text { sand } \\
& +0.0088163314 \text { silt }+0.0064338641 \text { clay } \\
& -0.3028160229 \rho_{\mathrm{b}}+1.79762 \times 10^{2} \text { sand }^{2} \\
& -3.134631 \times 10^{2} \text { silt }^{2}
\end{aligned}
$$

\section{Equations to Estimate van Genuchten Parameters}

\begin{tabular}{|c|c|c|c|c|}
\hline FAO textural class & $\theta_{\mathbf{r}}$ & $\boldsymbol{\theta}_{\mathrm{s}}$ & $\alpha$ & n \\
\hline \multicolumn{5}{|c|}{ Topsoils } \\
\hline Coarse & 0.025 & 0.403 & 0.0383 & 1.3774 \\
\hline Medium & 0.010 & 0.439 & 0.0314 & 1.1804 \\
\hline Medium fine & 0.010 & 0.430 & 0.0083 & 1.2539 \\
\hline Fine & 0.010 & 0.520 & 0.0367 & 1.1012 \\
\hline Very fine & 0.010 & 0.614 & 0.0265 & 1.1033 \\
\hline \multicolumn{5}{|c|}{$\underline{\text { Subsoils }}$} \\
\hline Coarse & 0.025 & 0.366 & 0.0430 & 1.5206 \\
\hline Medium & 0.010 & 0.392 & 0.0249 & 1.1689 \\
\hline Medium fine & 0.010 & 0.412 & 0.0082 & 1.2179 \\
\hline Fine & 0.010 & 0.481 & 0.0198 & 1.0861 \\
\hline Very fine & 0.010 & 0.538 & 0.0168 & 1.0730 \\
\hline
\end{tabular}

Wösten et al. (1999) analyzed the all-Europe database and derived the following PTFs to estimate van Genuchten parameters in Eq. [1]:

$$
\begin{aligned}
\theta_{\mathrm{s}}= & 0.7919+0.001691 \text { clay }-0.29619 \rho_{\mathrm{b}} \\
& -0.000001491 \mathrm{silt}^{2}+0.0000821 \mathrm{OM}^{2} \\
& +0.02427 / \text { clay }+0.01113 / \text { silt }+0.01472 \ln (\mathrm{silt}) \\
& -0.0000733 \text { OMclay }-0.000619 \rho_{\mathrm{b}} \text { clay } \\
& -0.001183 \rho_{\mathrm{b}} \mathrm{OM}-0.0001664 \text { topsoil silt }
\end{aligned}
$$

$$
\begin{aligned}
\alpha= & \exp [-14.96+0.03135 \text { clay }+0.0351 \text { silt } \\
& +0.646 \mathrm{OM}+15.29 \rho_{\mathrm{b}}-0.192 \text { topsoil }-4.671 \rho_{\mathrm{b}}^{2} \\
& -0.000781 \mathrm{clay}^{2}-0.00687 \mathrm{OM}^{2}+0.0449 / \mathrm{OM} \\
& +0.0663 \ln (\text { silt })+0.1482 \ln (\mathrm{OM})-0.04546 \rho_{\mathrm{b}} \text { silt } \\
& \left.-0.4852 \rho_{\mathrm{b}} \mathrm{OM}+0.00673 \text { topsoil clay }\right] \quad \text { [A42] }
\end{aligned}
$$

$n=1.0+\exp [-25.23-0.02195$ clay +0.0074 silt

$$
\begin{aligned}
& -0.1940 \mathrm{OM}+45.5 \rho_{\mathrm{b}}-7.24 \rho_{\mathrm{b}}^{2}+0.0003658 \text { clay }^{2} \\
& +0.002885 \mathrm{OM}^{2}-12.81 / \rho_{\mathrm{b}}-0.1524 / \mathrm{silt} \\
& -0.01958 / \mathrm{OM}-0.2876 \ln (\text { silt })-0.0709 \ln (\mathrm{OM}) \\
& -44.6 \ln \left(\rho_{\mathrm{b}}\right)-0.02264 \rho_{\mathrm{b}} \text { clay }+0.0896 \rho_{\mathrm{b}} \mathrm{OM} \\
& +0.00718 \text { topsoil clay }
\end{aligned}
$$

where topsoil is an ordinal variable having the value of 1 or of 0 . Parameter $m$ in Eq. [1] was computed as $1-1 / n$.

Wösten et al. (1999) also estimated average van Genuchten parameters (Table A3) for the FAO textural classes that are depicted in Fig. A1.

Vereecken et al. (1989) used a Belgian dataset to develop the following PTFs for the van Genuchten equation with $m=1$ :

$$
\begin{aligned}
& \theta_{\mathrm{s}}=0.81-0.283 \rho_{\mathrm{b}}+0.001 \text { clay } \\
\theta_{\mathrm{r}}= & 0.015+0.005 \text { clay }+0.014 \mathrm{OC}
\end{aligned}
$$

Table A3. Tabulated van Genuchten parameters by FAO textural classes (Wösten et al., 1999). 


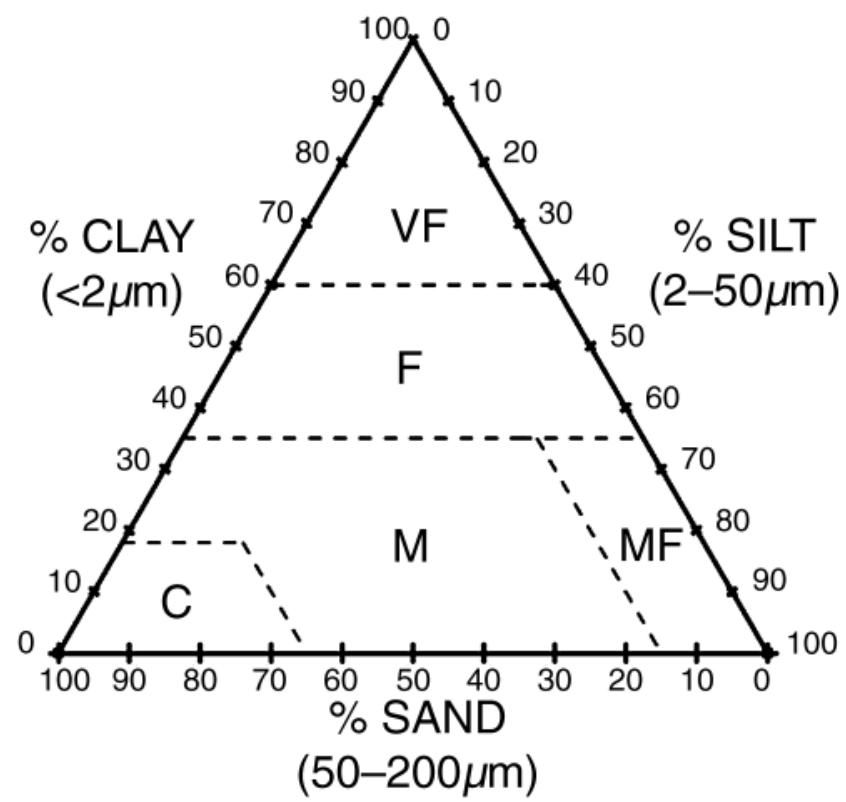

Fig. A1. Textural classification system according to the FAO Soil Map of Europe (1998). The FAO classes are: C (coarse), M (medium), MF (medium fine), F(fine), VF (very fine).

$$
\begin{aligned}
\alpha= & \exp (-2.486+0.025 \text { sand }-0.351 \text { clay } \\
& \left.-2.617 \rho_{\mathrm{b}}-0.023 \text { clay }\right) \\
n= & \exp (0.053-0.009 \text { sand }-0.013 \text { clay } \\
& \left.+0.00015 \text { sand }^{2}\right)
\end{aligned}
$$

Finally, Varallyay et al. (1982) applied the van Genuchten equation with $m=1$ and $\theta_{\mathrm{r}}=0$ to the Hungarian national database and found the following regression equations for $\mathrm{A}$ horizons:

$$
\begin{gathered}
\theta_{\mathrm{s}}=0.01\left(-56.4 \rho_{\mathrm{b}}+0.205 \text { clay }+123.79\right) \\
n=0.336 \rho_{\mathrm{b}}-0 . \\
\alpha=10^{-0.04701 \rho_{\mathrm{b}} \text { clay }-1.513 \rho_{\mathrm{b}}+0}
\end{gathered}
$$

and for $\mathrm{C}$ horizons:

$$
\begin{gathered}
\theta_{\mathrm{s}}=0.01\left(-46.8 \rho_{\mathrm{b}}+115.39\right) \\
n=0.00439 \rho_{\mathrm{b}} \text { clay }+0.625 \\
\alpha=10^{-0.03268 \rho_{\mathrm{b}} \text { clay }-0.865 \rho_{\mathrm{b}} \rho_{\mathrm{b}}-0.301}
\end{gathered}
$$

\section{ACKNOWLEDGMENTS}

This work was partly supported by Interagency Agreement RES-02-008 "Model Abstraction Techniques for Soil Water Flow and Transport" and also by the SAHRA Science Technology Center as part of NSF grant EAR-9876800.

\section{REFERENCES}

Baumer, O.M. 1992. Predicting unsaturated hydraulic parameters. p. 341-354. In M.Th. van Genuchten et al (ed.) Proc. Int. Workshop on Indirect Methods for Estimating the Hydraulic Properties of Unsaturated Soils. University of California, Riverside.
Brooks, R.H., and A.J. Corey. 1964. Hydraulic properties of porous media. Hydrol. Paper 3. Colorado State Univ., Fort Collins.

Bruand, A., D. Baize, and M. Hardy. 1994. Prediction of water retention properties of clayey soils: Validity of relationships using a single soil characteristic. Soil Use Manage. 10:99-103.

Burnham, K.P., and D.R. Anderson. 1998. Model selection and inference: A practical information-theoretic approach. Springer-Verlag, New York.

Campbell, G.S., and S. Shiozawa. 1992. Prediction of hydraulic properties of soils using particle size distribution and bulk density data. p. 317-328. In M.Th. van Genuchten et al (ed.) Proc. Int. Workshop on Indirect Methods for Estimating the Hydraulic Properties of Unsaturated Soils. University of California, Riverside.

Canarache, A. 1993. Physical-technological maps-A possible product of soil survey for direct use in agriculture. Soil Technol. 6:3-16.

FAO. 1998. World reference base for soil resources. Available at http:// www.fao.org/documents/show_cdr.asp?url_file=/docrep/W8594E/ W8594E00.htm (verified 20 Jan. 2006). FAO, Rome.

Gupta, S.C., and W.E. Larson. 1979. Estimating soil water retention characteristics from particle-size distribution, organic matter percent, and bulk density. Water Resour. Res. 15:1633-1635.

Hall, D.G.M., M.J. Reeve, A.I. Thomasson, and V.F. Wright. 1977. Water retention, porosity and density of field soils. Soil Surv. Tech. Monogr. 9. Rothamsted Experimental Station, Lawes Agricultural Trust, Harpenden, UK.

Hamill, T.M., J.A. Hansen, S.L. Mullen, and C. Snyder. 2005. Workshop on Ensemble Forecasting in the Short to Medium Range. Meeting Summary. Bull. Am. Meteorol. Soc. (in press).

Hamill, T.M., J.S. Whitaker, and X. Wei. 2004. Ensemble re-forecasting: Improving medium-range forecast skill using retrospective forecasts. Mon. Weather Rev. 132:1434-1447.

Heimovaara, T.J., and W. Bouten. 1990. A computer controlled 36channel time domain reflectometry system for monitoring soil water contents. Water Resour. Res. 26:2311-2316.

Houtemaker, P.L., L. Lefaivre, J. Derome, H. Ritchie, and H.L. Mitchell. 1996. A system simulation approach to ensemble prediction. Mon. Weather Rev. 124:1225-1242.

Jacques, D. 2000. Analysis of water flow and solute transport at the field scale. PhD thesis 454. Faculteit Landbouwkundige en Toegepaste Wetenschappen, K.U. Leuven, Belgium.

Jacques, D., J. Simunek, A. Timmerman, and J. Feyen, J. 2001. Calibration of the Richards' and convection-dispersion equations to fieldscale water flow and solute transport under rainfall conditions. J. Hydrol. 259:15-31.

Klute, A. 1965. Laboratory measurements of hydraulic conductivity of saturated soil. p. 210-220. In C.A. Black et al. (ed.) Methods of soil analysis. Part 1. Agron. Monogr. 9. ASA, Madison, WI.

Mallants, D., B.P. Mohanty, D. Jacques, and J. Feyen. 1996. Spatial variability of hydraulic properties in multi-layered soil profile. Soil Sci. 161:167-180.

Mayr, T., and N.J. Jarvis. 1999. Pedotransfer functions to estimate soil water retention parameters for a modified Brooks-Corey type model. Geoderma 91:1-9.

Molteni, F., R. Buizza, T.N. Palmer, and T. Petroliagis. 1996. The ECMWF ensemble prediction system: Methodology and validation. Q. J. R. Meteorol. Soc. 122:73-119.

Oosterveld, M., and C. Chang. 1980. Empirical relations between laboratory determinations of soil texture and moisture characteristic. Can. Agric. Eng. 22:149-151.

Opitz, D., and R. Maclin. 1999. Popular ensemble methods: An empirical study. J. Artif. Intell. Res. 11:169-198.

Pachepsky, Y.A., A.K. Guber, and D. Jacques. 2005a. Temporal persistence in vertical distributions of soil moisture contents. Soil Sci. Soc. Am. J. 69:347-352.

Pachepsky, Y.A., A.K. Guber, M.Th. van Genuchten, T.J. Nicholson, R.E. Cady, J. Simunek, and M.G. Schaap. 2005b. Model abstraction techniques for soil water flow and transport. NUREG/CR, U.S. Nuclear Regulatory Commission, Washington, DC (in press).

Pachepsky, Y.A., and W.J. Rawls (ed.). 2004. Development of pedotransfer functions in soil hydrology. Elsevier, Amsterdam.

Pachepsky, Ya.A., W.J. Rawls, and D. Gimenez. 2001. Comparison of soil water retention at field and laboratory scales. Soil Sci. Soc. Am. J. 65:460-462.

Pachepsky, Ya.A., W.J. Rawls, and D.J. Timlin. 1999. The current status 
of pedotransfer functions: Their accuracy, reliability, and utility in field- and regional-scale modeling. p. 223-234. In D.L. Corwin et al. (ed.) Assessment of non-point source pollution in the vadose zone. Geophys. Monogr. 108. AGU, Washington, DC.

Palmer, T.N., A. Alessandri, U. Andersen, P. Cantelaube, M. Davey, P. Délécluse, M. Déqué, E. Díez, F.J. Doblas-Reyes, H. Feddersen, R. Graham, S. Gualdi, J.-F. Guérémy, R. Hagedorn, M. Hoshen, N. Keenlyside, M. Latif, A. Lazar, E. Maisonnave, V. Marletto, A.P. Morse, B. Orfila, P. Rogel, J.-M. Terres, and M.C. Thomson. 2004. Development of a European multi-model ensemble system for seasonal tointer-annual prediction (DEMETER). Bull. Am. Meteorol. Soc. 85:853-872.

Petersen, G.W., R.L. Cunningham, and R.P. Matelski. 1968. Moisture characteristics of Pennsylvania soils: I. Moisture retention as related to texture. Soil Sci. Soc. Am. Proc. 32:271-275.

Rajkai, K., and G. Várallyay. 1992. Estimating soil water retention from simpler properties by regression techniques. p. 417-426. In M.Th. van Genuchten et al. (ed.) Proc. Int. Workshop on Indirect Methods for Estimating the Hydraulic Properties of Unsaturated Soils. University of California, Riverside.

Rawls, W.J., and D.L. Brakensiek. 1985. Prediction of soil water properties for hydrologic modeling. p. 293-299. In E.B. Jones and T.J. Ward (ed.) Proc. Symp. Watershed Management in the Eighties, Denver, CO. 30 Apr.-1 May 1985. Am. Soc. Civil Eng., New York.

Rawls, W.J., D.L. Brakensiek, and K.E. Saxton. 1982. Estimation of soil water properties. Trans. ASAE 25:1316-1320.

Rawls, W.J., D.L. Brakensiek, and B. Soni. 1983. Agricultural management effects on soil water processes. Part I. Soil water retention and Green-Ampt parameters. Trans. ASAE 26:1747-1752.

Rawls, W.J., D. Giménez, and R. Grossman. 1998. Use of soil texture, bulk density and slope of the water retention curve to predict saturated hydraulic conductivity. Trans. ASAE 41:983-988.

Saxton, K.E., W.J. Rawls, J.S. Romberger, and R.I. Papendick. 1986. Estimating generalized soil-water characteristics from texture. Soil Sci. Soc. Am. J. 50:1031-1036.

Schaap, M.G., and F.J. Leij. 1998. Database related accuracy and uncertainty of pedotransfer functions. Soil Sci. 163:765-779.
Schaap, M.G. 2004. Graphic user interfaces for pedotransfer functions p. 349-356. In Y.A. Pachepsky and W.J. Rawls (ed.) Development of pedotransfer functions in soil hydrology. Elsevier, Amsterdam.

Simunek, J., M. Sejna, and M.Th. van Genuchten. 1998. The HYDRUS-1D software package for simulating the one-dimensional movement of water, heat and multiple solutes in variably-saturated media. Version 2.0, IGWMC-TPS-70. International Ground Water Modeling Center, Colorado School of Mines, Golden.

Tietje, O., and M. Tapkenhinrichs. 1993. Evaluation of pedotransfer functions. Soil Sci. Soc. Am. J. 57:1088-1095.

Tomasella, J., and M.G. Hodnett. 1998. Estimating soil water retention characteristics from limited data in Brazilian Amazonia. Soil Sci. 163:190-202.

van Genuchten, M.Th. 1980. A closed-form equation for predicting the hydraulic conductivity of unsaturated soils. Soil Sci. Soc. Am. J. 44:892-898.

Varallyay, G., Rajkai K., Ya.A. Pachepsky, and R.A. Shcherbakov. 1982. Mathematical description of soil water retention curve. (In Russian.) Pochvovedenie 4:77-89.

Vereecken, H., J. Maes, J. Feyen, and P. Darius. 1989. Estimating the soil moisture retention characteristics from texture, bulk density and carbon content. Soil Sci. 148:389-403.

Williams, J., P. Ross, and K. Bristow. 1992. Prediction of the Campbell water retention function from texture, structure, and organic matter. p. 427-442. In M.Th. van Genuchten et al (ed.) Proc. Int. Workshop on Indirect methods for Estimating the Hydraulic Properties of Unsaturated Soils. University of California, Riverside.

Wösten, J.H.M., A. Lilly, A. Nemes, and C. Le Bas. 1999. Development and use of a database of hydraulic properties of European soils. Geoderma 90:169-185.

Wösten, J.H.M., Y.A. Pachepsky, and W.J. Rawls. 2001. Pedotransfer functions: Bridging the gap between available basic soil data and missing soil hydraulic characteristics. J. Hydrol. 251:123-150.

Ye, M., S.P. Neuman, and P.D. Meyer. 2004. Maximum likelihood Bayesian averaging of spatial variability models in unsaturated fractured tuff. Water Resour. Res. 40:W05113. doi:10.1029/2003WR002557. 